\title{
High strain-rate behavior and deformation mechanism of a multi- layer composite textured AZ31B Mg alloy plate
}

\author{
Weigui Zhang a, d, *, Sai Liu ${ }^{\text {b }}$, Kun Li ${ }^{c}$, Peijie Li ${ }^{\text {d }}$, Junfeng Qi ${ }^{\text {a }}$, Zhen Wang ${ }^{\text {a }}$, Yi Chen ${ }^{\text {a }}$, \\ Husheng Zhang ${ }^{\text {e, Li Meng }}{ }^{\mathrm{f}, * *}$ \\ a Beijing Spacecrafts, China Academy of Space Technology, Beijing 100094, China \\ ${ }^{\mathrm{b}}$ Research and Development Center, China Academy of Launch Vehicle Technology, Beijing 100076, China \\ ${ }^{\mathrm{c}}$ Laboratory for Excellence in Advanced Steel Research, Department of Metallurgical, Materials and Biomedical Engineering, University of Texas, EI Paso, TX \\ 79968-0520, USA \\ ' Department of Mechanical Engineering, Tsinghua University, Beijing 100084, China \\ e State Key Laboratory of Nonlinear Mechanics, Institute of Mechanics, Chinese Academy of Sciences, Beijing 100190, China \\ ${ }^{\mathrm{f}}$ Central Iron \& Steel Research Institute, Beijing 100081, China
}

\section{A R T I C L E I N F O}

\section{Article history:}

Received 13 November 2017

Received in revised form

18 March 2018

Accepted 20 March 2018

Available online 21 March 2018

\section{Keywords:}

AZ31 B Mg alloy

Multi-layer composite textures

High strain rate

Twinning and slip

Energy absorption capacity

\begin{abstract}
A B S T R A C T
There are currently very few studies on the high strain-rate properties of Mg alloys with multi-layer composite textures under dynamic loading. In present study, a multi-layer composite textured AZ31B $\mathrm{Mg}$ alloy plate was fabricated using the asymmetric twin-roll casting process. The high strain-rate $\left(\sim 10^{3}\right.$ $\mathrm{s}^{-1}$ ) deformation behaviors of the AZ31B plate along the normal direction (ND) were investigated using split-Hopkinson pressure bar technique. The microstructural evolution and deformation mechanism were analyzed by optical microscopy, scanning electron microscopy, X-ray diffraction, and transmission electron microscopy methods. The experimental results show that the mechanical behaviors exhibit a power-law hardening response under high strain-rate deformation. The flow stress generally increases with increasing strain rate, whereas the strain-hardening rate decreases with increasing strain. An interesting feature is that the maximum flow stress at high strain rates is much lower than that at its corresponding quasi-static counterpart. Microstructure analysis demonstrates that the characteristic layered texture and microstructure along the ND determine its mechanical behavior. The plastic deformation is mainly controlled by the basal-type texture, where the predominant deformation mechanism is dislocation slip. Dynamic recrystallization (DRX) occurred unevenly in the material during dynamic deformation, resulting in a moderate increase in ductility. The fracture behaviors change from brittle fracture to ductile fracture as the strain rate increases. The energy absorption capacity is therefore enhanced due to the occurrence of both DRX and the brittle-ductile transition at high strain rates.
\end{abstract}

(c) 2018 Elsevier B.V. All rights reserved.

\section{Introduction}

Magnesium (Mg) and its alloys are desirable structural materials for lightweight systems due to their low density and high specific strength. The use of Mg alloys has increased significantly in the automotive, aerospace and aeronautics, defense, and other energyintensive industries to meet the stringent requirements for lightweight design and manufacturing [1-4]. These $\mathrm{Mg}$ alloy

\footnotetext{
* Corresponding author. Beijing Spacecrafts, China Academy of Space Technology, Beijing 100094, China.

** Corresponding author.

E-mail addresses: CASC529@163.com (W. Zhang), li_meng@126.com (L. Meng).
}

components are placed in rigorous loading environments, such as shock, impact and vibration, where very high strain rates (on the order of $10^{3} \mathrm{~s}^{-1}$ ) are commonly achieved. More attention should therefore be paid to the mechanical responses over a wide range of strain rates to ensure the $\mathrm{Mg}$ alloy components can withstand these highly variable environments. A good knowledge of the dynamic mechanical properties and deformation mechanisms is also crucial to optimize the mechanical behavior of the $\mathrm{Mg}$ alloys, thus providing significant guidance for the optimization and fabrication of $\mathrm{Mg}$ alloy components that are suitable for high strain-rate loading conditions.

Mg has a hexagonal close-packed (HCP) crystal structure, with a $c / a$ ratio that is slightly less than the ideal value of 1.633 . The 
mechanical behavior and deformation mechanisms of $\mathrm{Mg}$ and its alloys at low strain rates have been thoroughly investigated [5-15]. The shapes of the mechanical curves generally have sigmoidal (concave up) and power-law (concave down) characteristics under uniaxial compression or tension at low strain rates, respectively. The sigmoidal shape is due to the activation of $\{10-12\}$ extension twinning in the early deformation stage, and the power-law shape is due to dislocation slip during deformation [7-12]. It is well known that the macroscopic mechanical behaviors of $\mathrm{Mg}$ and its alloys are strongly dominated by their microscopic deformation mechanisms. Dislocation slip and twinning are the predominant deformation mechanisms in $\mathrm{Mg}$ and its alloys. The main dislocation slip systems are the $\{0001\} 11-20$ basal slip system, $\{10-10\} 11-20$ prismatic slip system, and $\{10-11\} 11-20$ pyramidal slip system [8]. Note that all the slip systems mentioned above have the $a=[11-20]$ type Burgers vector, such that they cannot accommodate plastic deformation in the $c=[0001]$ direction. The $\{11-22\}-1-123$ pyramidal $c+a$ slip system has a Burgers vector containing both the $c$ and $a$ components, thus allowing deformation in the $c$ direction.

$\mathrm{Mg}$ and its alloys do not have a sufficient number of independent slip systems to accommodate general plastic deformation due to their HCP type crystal structure. Therefore, twinning plays a critical role in plastic deformation, with the $\{10-12\} 10-11$ extension twinning mode and $\{10-11\} 10-12$ contraction twinning mode being the most common modes in $\mathrm{Mg}$ and its alloys. Extension twinning is favored when the $c$-axis is under tension, which accommodates tensile deformation in the $c$ direction and reorients the parent lattice by approximately $86.3^{\circ}$ [11]. Contraction twinning is favored when the $c$-axis is under compression, which accommodates compressive deformation in the $c$ direction and reorients the parent lattice by approximately $56.2^{\circ}$ [11].

Although the activation of the slip system or twinning system is affected by many factors, such as the loading orientation with respect to the $c$-axis, deformation temperature, and strain rate, the critical resolved shear stress (CRSS) is the key factor in determining the significance of each mechanism. The generally accepted CRSS values for slip systems and twinning systems in $\mathrm{Mg}$ and its alloys are: $\mathrm{CRSS}_{\text {basal slip }}<\mathrm{CRSS}_{\text {extension twinning }}<\mathrm{CRSS}_{\text {prismatic slip }}<\mathrm{CRSS}_{\text {pyramidal }}$ slip $<\mathrm{CRSS}_{\text {contraction twinning }}[8,14]$. The plastic deformation of Mg alloys is generally carried out through basal slip and extension twinning due to their low CRSS. Non-basal slip is difficult to be activated because of its high CRSS. Furthermore, the deformation temperature has a remarkable influence on CRSS. It is found that the CRSS for basal slip and extension twinning are temperature independent, whereas the CRSS for non-basal slip obviously decreases with increasing temperature. The deformation ability of $\mathrm{Mg}$ alloys at high temperatures is greatly improved, with dynamic recrystallization (DRX) taking place at temperatures above $200{ }^{\circ} \mathrm{C}$ during deformation, thus enhancing the ductility of the Mg alloys [15].

The application of $\mathrm{Mg}$ alloys in the aerospace, aeronautics, and defense industries requires thorough studies of the mechanical behaviors, deformation mechanisms, and energy absorption capacity under high strain-rate $\left(\sim 10^{3} \mathrm{~s}^{-1}\right)$ loading. The high strainrate properties and deformation mechanisms of $\mathrm{Mg}$ and its alloys, including pure $\mathrm{Mg}$ [16], AZ series [17-22], AM series [23], ZK series [24,25], and rare-earth-containing Mg alloys [26,27], have recently been extensively investigated, with the analyzed samples processed by extrusion, rolling, or casting. Dixit et al. [16] investigated the deformation mechanism and microstructural evolution of extruded pure $\mathrm{Mg}$ under dynamic $\left(\sim 10^{3} \mathrm{~s}^{-1}\right)$ compression along the extrusion direction (ED). A significant increase in the density of $c+$ $a$ dislocations is observed in pure $\mathrm{Mg}$ after deformation. It is found that both $\{10-12\}$ extension twinning and non-basal dislocation slip are needed to accommodate plastic deformation. Ulacia et al.
[17] and Dudamell et al. [18] analyzed the dynamic mechanical behavior and microstructural evolution of AZ31 sheet. The shapes of the true strain-true stress curves exhibit both concave down (under tensile loading) and concave up (under compressive loading) characteristics. The concave down shape is due to dislocation slip during deformation, whereas the concave up shape is due to the activation of extension twinning in the early deformation stage. The formation and development of $\{10-12\}$ extension twinnings are dramatically enhanced at high strain rates, with the multiplication and accumulation of dislocations occurring due to this increasing strain. Prasad et al. [28] published a critical review of the dynamic mechanical behaviors and failure mechanisms of $\mathrm{Mg}$ and its alloys. They suggested that the flow stress is insensitive to strain rate if the deformation is mainly dominated by $\{10-12\}$ extension twinning, whereas the flow stress increases with increasing strain rate if the deformation is mainly controlled by dislocation slip. Furthermore, the flow localizes into shear bands, which leads to a failure during the high strain-rate deformation.

There is currently almost no information in the literature that discusses the dynamic mechanical behavior of $\mathrm{Mg}$ alloys with multi-layer composite textures. The Mg alloy textures are characterized by a layered distribution along the thickness direction, particularly for thick plates. Different types of textures lead to the appearance of the multiple deformation mechanisms during plastic deformation, such that the deformation behaviors of the entire material can be quite complicated. Asymmetric twin-roll casting (ATRC) is a promising quick process and near-net-shape sheet metal processing technology that can significantly optimize the microstructure and improve the mechanical properties of the material $[29,30]$. The velocity of the upper and lower rolls is different in the ATRC process, which leads to an inhomogeneous distribution of the stress and temperature fields along the thickness direction of the plate. This heterogeneity is even more pronounced for the larger plate thicknesses. Current studies on the ATRC of Mg alloys have mainly focused on optimizing the process, and determining the microstructure and performance control of the materials. It is therefore necessary to investigate the dynamic mechanical behaviors and deformation mechanisms of multi-layered composite textured Mg alloy plates at high strain rates to capture the effect of these composite textures on the mechanical responses of the material.

Here a multi-layer composite textured AZ31B Mg alloy plate was fabricated using ATRC. The mechanical behaviors of AZ31B along the normal direction (ND) at high strain rates were investigated using a split-Hopkinson pressure bar (SHPB) apparatus. The deformation mechanisms, microstructural evolution, and fracture behavior of the alloy plate were analyzed utilizing optical microscopy (OM), scanning electron microscopy (SEM), x-ray diffraction (XRD), and transmission electron microscopy (TEM). These new results significantly complement the current knowledge regarding the dynamic mechanical behavior of wrought Mg alloys under high strain-rate loading.

\section{Experimental procedure}

\subsection{Materials}

An AZ31B Mg alloy plate with initial thickness of $8 \mathrm{~mm}$ was fabricated via the ATRC process. The AZ31B plate was then annealed at $450^{\circ} \mathrm{C}$ for $6 \mathrm{~h}$ to produce fine recrystallized grains. The chemical compositions of the AZ31B plate were measured with an X-ray fluorescence spectrometer (XRF), and are presented in Table 1. The stress field in the AZ31B plate was asymmetrically distributed along the thickness direction during the processing, resulting in an inhomogeneous distribution of microstructures along the plate ND. 
Table 1

The chemical compositions of the AZ31B Mg alloy, detected by XRF (wt.\%).

\begin{tabular}{llllll}
\hline Element & $\mathrm{Mg}$ & $\mathrm{Al}$ & $\mathrm{Zn}$ & $\mathrm{Mn}$ & Other \\
Content & 95.572 & 3.235 & 0.871 & 0.311 & 0.012 \\
\hline
\end{tabular}

The microstructures of the AZ31B plate therefore need to be characterized from the upper layer through the center to the lower layer. Fig. 1a shows a schematic diagram of the cut layers in the AZ31B plate, with the initial microstructures from the longitudinal section (RD-ND) of the AZ31B plate shown in Fig. 1b-d. The microstructures in the upper area and lower area of the plate near the rolls are composed of fine equiaxed grains (Fig. $1 \mathrm{~b}$ and d), with a larger amount of coarse grains present in the central area of plate that are ascribed to the lower cooling rate in comparison to the plate surface (Fig. 1c).

The orientation distribution function (ODF) was used to characterize the initial crystallographic textures of the upper, onequarter, central, three-quarter, and lower layers of the AZ31B Mg alloy plate. ODF sections with $\varphi_{2}=0^{\circ}, 30^{\circ}$ were used to characterize the material textures because of the symmetry of the hexagonal structure. The results of the crystallographic texture analysis of the AZ31B plate are shown in Fig. 2. The textures of the upper and lower layers of the plate are shown in Fig. 2a and e, respectively, which indicate near basal-type textures that possess the $\{0001\} 10-10$ and $\{0001\} 11-20$ dominant components, with the $c$-axis tilted away from the ND and toward the transverse direction (TD). The one-quarter and three-quarter layers of the plate possess weak basal-type textures (Fig. $2 \mathrm{~b}$ and d), where the $c$-axis obviously deviates from the ND. The central layer of the plate has a prismatic-type texture and a $\{10-10\} 11-20$ dominant component (Fig. 2c), with the $c$-axis perpendicular to the ND.

It is clear that the crystallographic textures underwent a gradual change from basal-type to prismatic-type textures within the AZ31B Mg alloy plate. The texture exhibits a layered distribution along the plate ND. The textures indicate that this is a plate having multi-layer composite textures (MCT), and is hereafter referred to as MCT AZ31B.

\subsection{Mechanical testing}

Quasi-static $\left(\sim 10^{-4} \mathrm{~s}^{-1}\right)$ compression tests of the MCT AZ31B were carried out at room temperature and up to failure along the plate ND. Cylindrical samples with a $4-\mathrm{mm}$ diameter and $8-\mathrm{mm}$ height were used. These tests were conducted in an electronic universal testing machine (ZWICKZ020). The high strain-rate $\left(\sim 10^{3}\right.$ $\mathrm{s}^{-1}$ ) compression tests were conducted up to failure or up to a given strain using a SHPB apparatus, which is an established dynamic mechanical test technology. Full details of this test technique have been described in Ref. [31] and are not presented here. The given strain was achieved by the deformation "frozen" technique, which uses the stop-ring of a hardened steel surrounding the sample to interrupt the deformation process. Thus, the microstructure was "frozen" at a given strain for subsequent observation and analysis. Note that care must be taken when conducting these experiments to ensure that the stop-ring does not come in contact with the lateral sides of the test samples. The sizes of the stop-ring are designed to have an inner diameter of $7 \mathrm{~mm}$, an outer diameter of $13 \mathrm{~mm}$, and a thickness of $2.4 \mathrm{~mm}$. The controlled strain test was carried out at a plastic strain of approximately $2.7 \%$. This value was
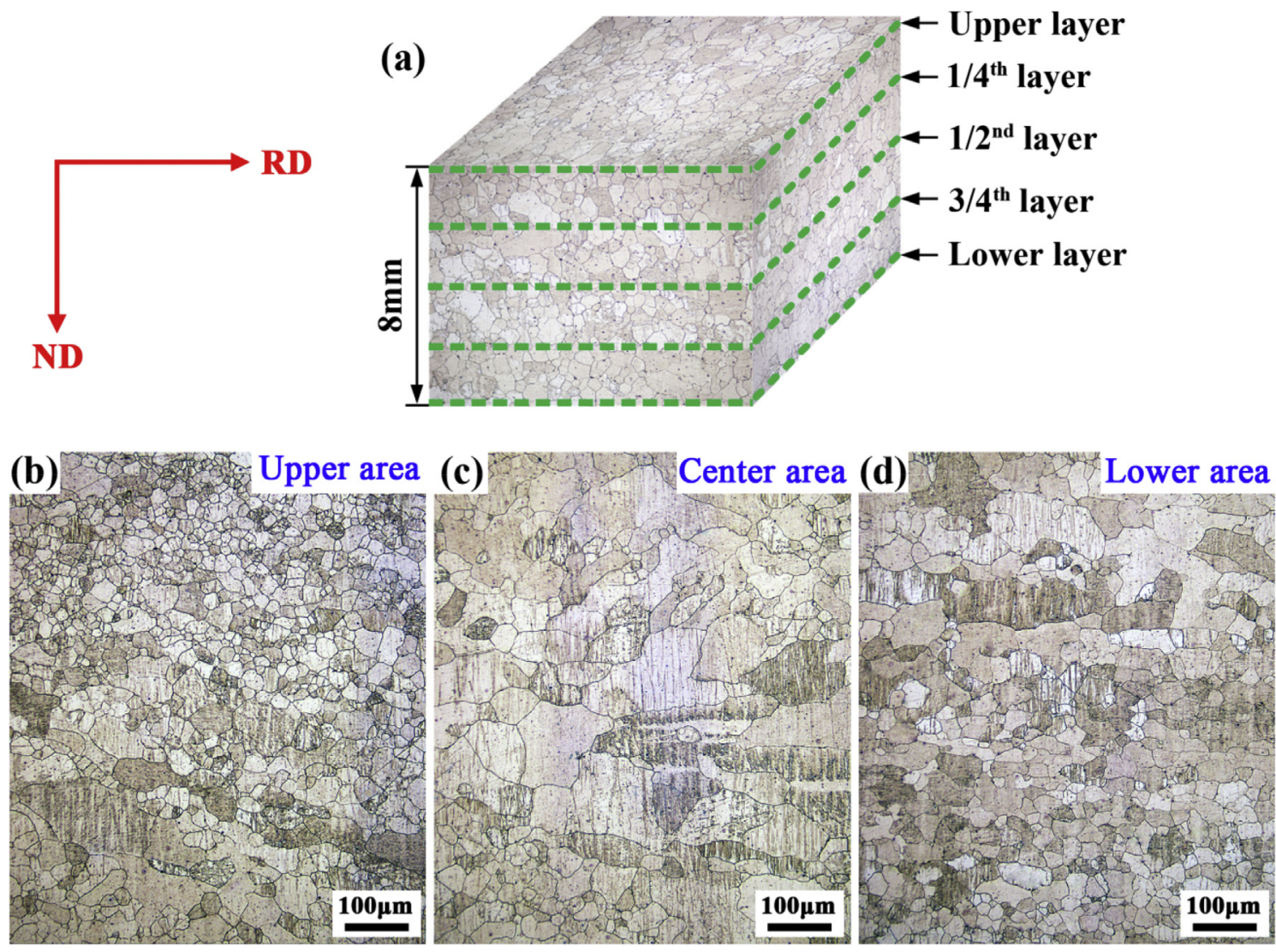

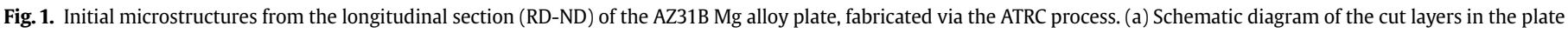
along the thickness direction. (b) Upper area of the plate. (c) Central area of the plate. (d) Lower area of the plate. 
(a)

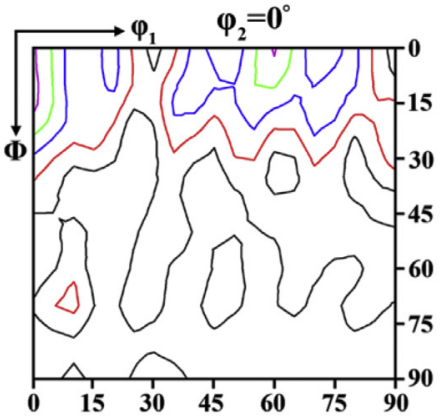

(b)

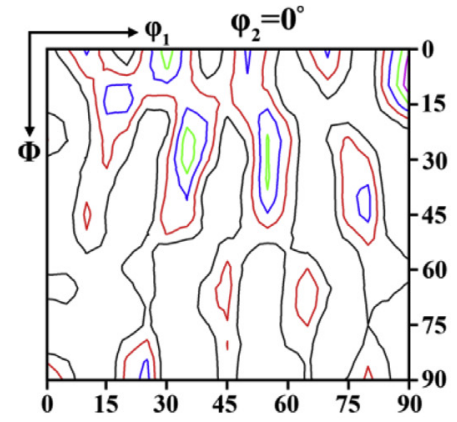

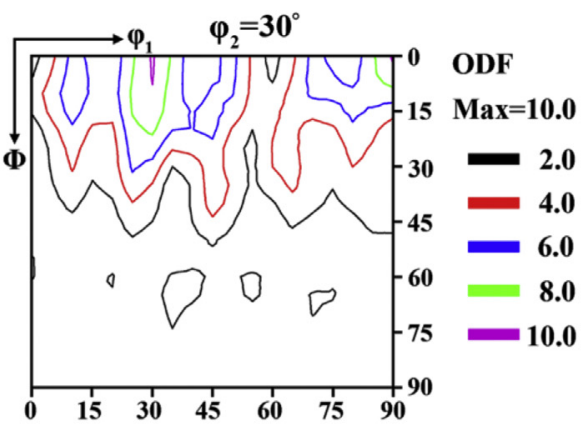

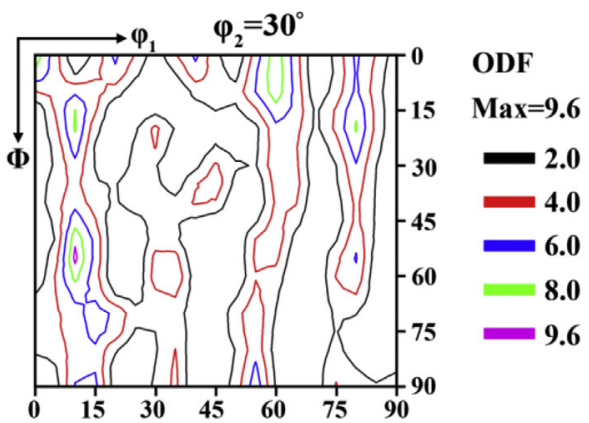

(c)

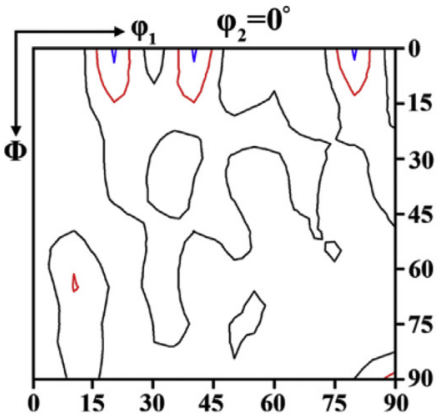

(d)

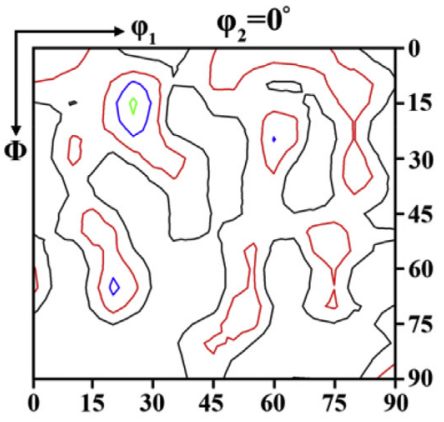

(e)

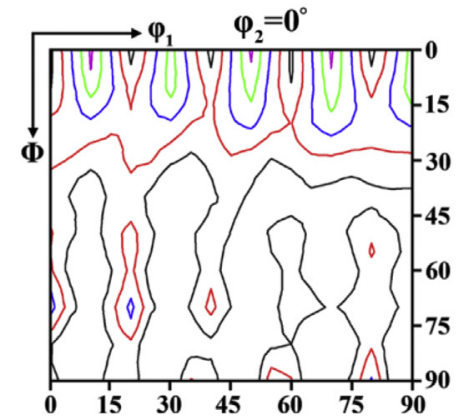

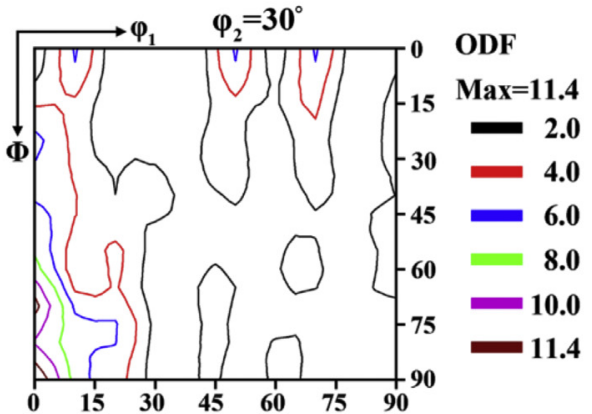
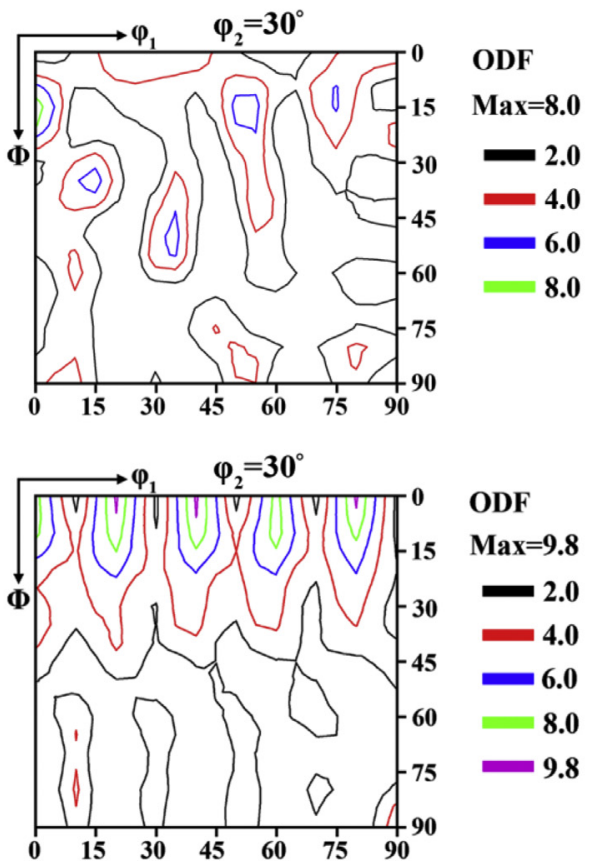

\section{Upper layer}

$1 / 4^{\text {th }}$ layer

\section{$1 / 2^{\text {nd }}$ layer}

$3 / 4^{\text {th }}$ layer

\section{Lower layer}

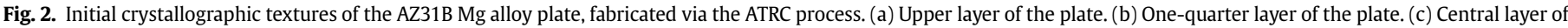
the plate. (d) Three-quarter layer of the plate. (e) Lower layer of the plate. 
chosen since the plastic deformation is in the initial stage at $\sim 2.7 \%$ strain.

The SHPB samples were machined from the MCT AZ31B plate along the ND, where the axial direction of the cylindrical sample was parallel to the plate ND, since the most typical engineering application of the Mg alloy components involves subjecting them to external loading along the plate ND.

Three kinds of test samples were designed for the dynamic mechanical tests to cover a wide range of strain rates. The samples for the controlled strain tests had a 4-mm diameter and 3-mm length. The samples that underwent strain rates in the $1000-4000 \mathrm{~s}^{-1}$ range had an $8-\mathrm{mm}$ diameter and 6-mm length. The samples that underwent high strain rates $\left(>4000 \mathrm{~s}^{-1}\right)$ had a $5.33-\mathrm{mm}$ diameter and $4-\mathrm{mm}$ length. All the test samples were machined using a computer-operated numerical control milling machine and possessed a surface roughness of $1.6 \mu \mathrm{m}$. The configurations of the samples used for the SHPB tests, along with the impact direction relative to the samples, are shown in Fig. 3a. The aspect ratio (length to diameter) of all the SHPB samples is 0.75:1. Representative incident, reflected, and transmitted waves obtained from the SHPB tests are shown in Fig. 3b. Three to four tests were conducted for both quasi-static and high strain-rate compression, with the averages of the results reported to check the reproducibility of the results. Three sets of high strain rate tests were done on the MCT AZ31B samples at a strain rate of $1326 \mathrm{~s}^{-1}$, with the average value of the curves used (Fig. $3 \mathrm{c}$ ). It should be noted that the elastic portions of the mechanical curves in Fig. $3 c$ have been removed since the SHPB test does not accurately capture the elastic response, which will be discussed in a later section. A similar trend was observed for the other SHPB samples, and the same method was used to report their typical true stress-true strain responses.

\subsection{Microstructural examination}

The Microstructural analysis of the MCT AZ31B samples, both before and after the quasi-static $\left(\sim 10^{-4} \mathrm{~s}^{-1}\right)$ and high strain-rate $\left(\sim 10^{3} \mathrm{~s}^{-1}\right)$ compression tests, was conducted using an optical microscope (OLYMPUS DP72). The OM samples were first polished to 2000 grit, followed by polishing with a $0.5-\mathrm{mm}$ diamond paste. The samples were then chemically etched for $3-10 \mathrm{~s}$ with a mixed solution that consisted of $5 \mathrm{~g}$ picric acid $\left(\left(\mathrm{NO}_{2}\right)_{3} \mathrm{C}_{6} \mathrm{H}_{2} \mathrm{OH}\right), 10 \mathrm{~mL}$ acetic acid $\left(\mathrm{CH}_{3} \mathrm{COOH}\right), 100 \mathrm{~mL}$ anhydrous ethanol $\left(\mathrm{CH}_{3} \mathrm{CH}_{2} \mathrm{OH}\right)$, and $10 \mathrm{~mL}$ water $\left(\mathrm{H}_{2} \mathrm{O}\right)$. The erosion time was $3-10 \mathrm{~s}$, which was adjusted according to the degree of deformation that the test sample underwent. Deionized water was used to wash and clean the samples during the preparation to prevent oxidation. A HITACHI S-4800 field emission SEM was used to characterize the fracture morphology of the samples after quasi-static and high strainrate deformation, with an acceleration voltage of $20-30 \mathrm{KV}$ and secondary electronic observation mode.

XRD analysis of the MCT AZ31B samples, before and after the quasi-static and high strain-rate tests, was conducted to measure the crystallographic textures. A Bruker D8 advance diffractometer, with $\mathrm{Cu} \mathrm{K} \alpha$ radiation and a LynxEye 1D detector, was employed for the analysis. Five incomplete pole figures (PFs), namely $\{0002\}$, $\{10-10\},\{10-11\},\{10-12\}$, and $\{11-20\}$, were first measured, and the ODFs were then calculated using the PF data. The ODF sections with $\varphi_{2}=0^{\circ}, 30^{\circ}$ were used to characterize the material textures due to the symmetry of the hexagonal structure. The dimensions of the samples used to characterize the initial texture were $25 \mathrm{~mm} \times 20 \mathrm{~mm} \times 2 \mathrm{~mm}$. The initial texture of AZ31B was acquired from the RD-TD section of plate. The textures of the compression state were obtained from the compression plane of the test samples. The angle between the $c$-axis and plate ND was determined using a Wulff net.

TEM analysis was performed on the microstructures (dislocations and twins) of the MCT AZ31B samples after a high strain-rate deformation. The TEM samples were cut along the compression plane of the test samples using a wire cutting. These sections were then ground to a thickness of $\sim 50-60 \mu \mathrm{m}$ using SiC paper, with 3$\mathrm{mm}$ disks punched from the foils. The foils were electropolished using a twin-jet polisher to perforation using a solution of $3 \mathrm{vol} \%$ (a)
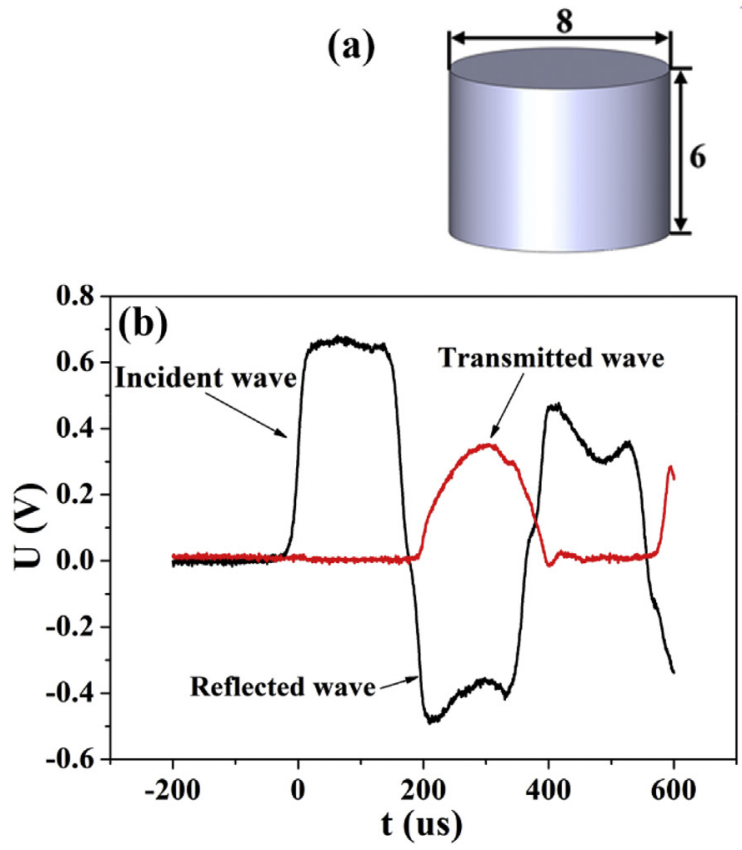
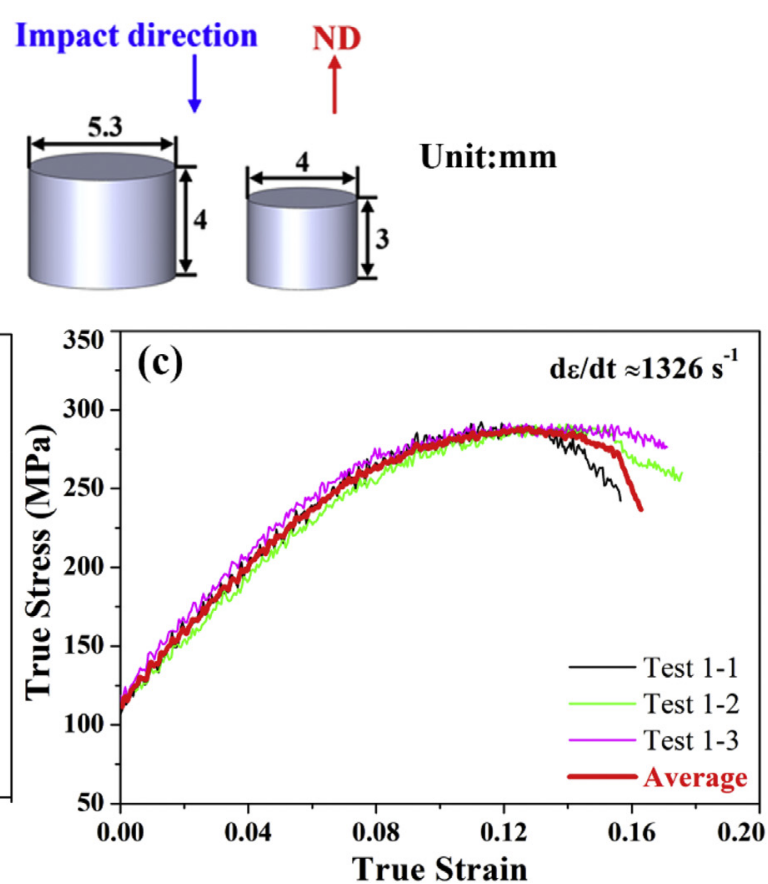

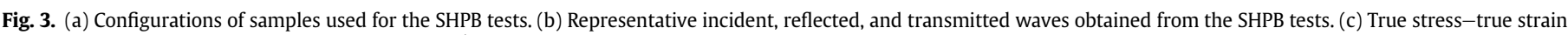
curves of the MCT AZ31B at a strain rate of $1326 \mathrm{~s}^{-1}$. 
perchloric acid in ethanol. The samples were then cleaned by ion milling for $0.5-1 \mathrm{~h}$, with liquid nitrogen applied during the milling. The TEM observations were made with a FEI Tecnai G2 F20 operating at $200 \mathrm{kV}$.

Microhardness measurements were made after quasi-static and high strain-rate deformation using a FM-800 micro-hardness tester to investigate the microstructural evolution of the mechanical properties of the MCT AZ31B. A diamond indenter with a $50 \mathrm{~g}$ load was employed using a $15 \mathrm{~s}$ indentation time.

\section{Results and discussions}

\subsection{Mechanical behaviors}

The true stress-true strain curves of the MCT AZ31B under compression in the ND at quasi-static and high strain rates $\left(d \varepsilon / d t \approx 1326-5107 s^{-1}\right)$ and room temperature are shown in Fig. 4. Note that the elastic portion $(\varepsilon<0.005)$ of the initial mechanical curves obtained from the SHPB tests has been removed since the SHPB tests do not accurately represent the elastic response. It is reasonable to determine the yield stress from the intersection of the dynamic true stress-true strain curve and the $0.5 \%$ offset line $[17,22]$, such that the $x$-axis coordinates in Fig. 4 only represent the pure plastic strain of AZ31B during deformation. The mechanical behaviors of the MCT AZ31B under quasistatic and high strain-rate compression are basically similar, exhibiting a power-law hardening response (Fig. 4). The flow stress at high strain rates is higher than that at quasi-static rates for plastic strain with $\varepsilon<0.10$, such that the flow stress generally increases with increasing strain rate. The mechanical behavior at high strain rates exhibits adiabatic softening for plastic strain with $\varepsilon>0.10$, especially when the loading strain rate is increased to 5107 $\mathrm{s}^{-1}$, leading to the adiabatic softening effect being more significant. Furthermore, an interesting feature is that the maximum flow stress $(305-320 \mathrm{MPa})$ at high strain rates is lower than that $(335 \mathrm{MPa})$ at quasi-static rates, with the maximum flow stress of metal alloys under dynamic loading being significantly higher than that under quasi-static loading due to a greater degree of strain rate hardening. This conclusion has been confirmed by many studies on

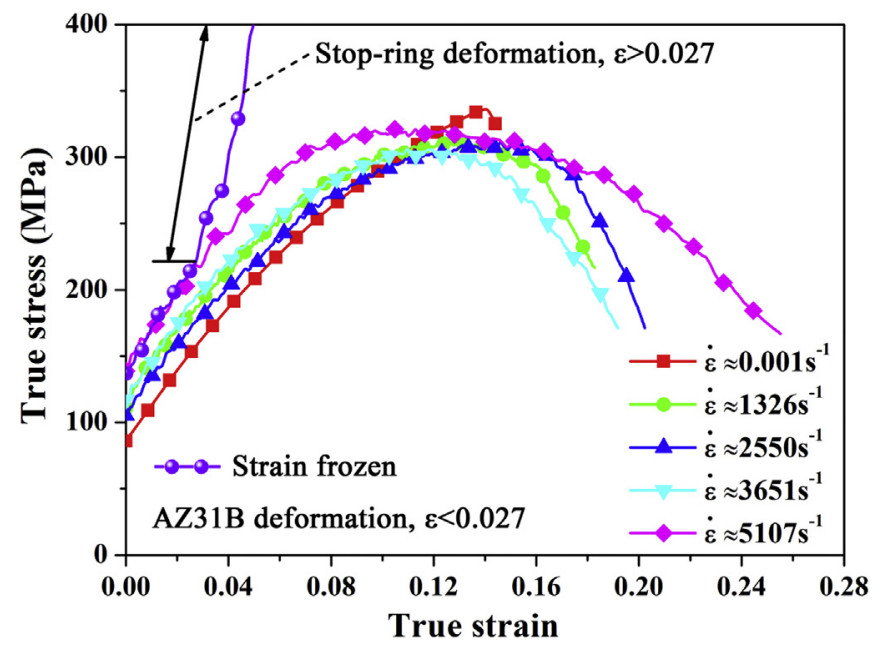

Fig. 4. True stress-true strain curves of the MCT AZ31B under compression in the ND at quasi-static and high strain rates. The measurements were made at room temperature. Note that the elastic portion $(\varepsilon<0.005)$ of the initial dynamic mechanical curves, obtained from the SHPB tests, has been removed since the SHPB test does not accurately represent the elastic response. The $x$-axis coordinates in Fig. 4 only represent the pure plastic strain of AZ31B during deformation. the dynamic $\left(\sim 10^{3} \mathrm{~s}^{-1}\right)$ mechanical properties of $\mathrm{Mg}$ and its alloys [17,20,22-24,26,28]. The dynamic mechanical behavior of the MCT AZ31B exhibits an "abnormal behavior", which will be discussed in a following section. It should be noted that the failure behavior of the MCT AZ31B at high strain rates is significantly different from that at quasi-static rates. The humps at the peak flow stress of the dynamic mechanical curves become wider, which indicates that the material undergoes a ductile fracture under high strain-rate deformation. The ductile fracture behavior will be explained in combination with the microstructural analysis later in the paper.

The macroscopic mechanical behavior of a material is dominated by its microscopic deformation mechanism. The schematic diagram of the initial textures for the upper, one-quarter, central, three-quarter, and lower layers of the AZ31B plate, along with the loading orientation with respect to the $c$-axes, shown in Fig. 5, were analyzed to further understand the dynamic mechanical behavior of the MCT AZ31B. It is apparent in Fig. 5a that the textures transformed gradually from the basal-type for the upper and lower layers to the prismatic-type for the central layer. It can therefore be considered that there are two types of textures in the MCT AZ31B, the basal-type texture for the outer area of the plate and the prismatic-type texture for the central area of the plate, which are marked as T1 and T2, respectively, in Fig. 5b. The T1 texture favors dislocation slip (basal and non-basal dislocations) activation, and the T2 texture favors $\{10-12\}$ extension twinning activation when under compression along the ND, which is indicative of a typical power-law hardening response with dislocation slip as the main deformation mechanism [17,22]. The effect of $\{10-12\}$ extension twinning on the mechanical behavior is very limited. Numerous studies [16-18,20,22,24] have shown that the mechanical behaviors of materials with a HCP structure exhibit the sigmoidal hardening response when the plastic deformation is dominated by an extension twinning, with the power-law hardening curve being a signature of the dislocation slip mechanism.

The MCT AZ31B textures exhibit a layered distribution along the plate ND. Different textures indicate appearance of the different deformation mechanisms during deformation, which will affect the mechanical behaviors of the material. The stress-strain curves in Fig. 4 indicate that the mechanical behavior of the MCT AZ31B is mainly determined by its basal-type texture, with the prismatictype texture in the central area of the plate having no significant effect on the mechanical behavior. It is noted that the T1 texture in Fig. $5 \mathrm{~b}$ is also favorable for both contraction and secondary twinning, in addition to the dislocation slip, when the plate is under compression along the ND. However, many studies [32,33] have indicated that traces of these types of twins are only observed in very localized regions, often being close to the fracture surface during compression along the $c$-axis, But their net contribution to the total deformation is extremely limited [18]. Thus, it is now widely accepted that most of the compression strain along the $c$-axis is accommodated by non-basal dislocation slip [6,16,34].

The dynamic mechanical behaviors of the MCT AZ31B exhibit a power-law hardening response under compression along the ND. The flow stress and strain hardening both increase with increasing strain for plastic strain with $\varepsilon<0.10$. However, adiabatic softening occurred for plastic strain with $\varepsilon>0.10$, resulting in a moderate increase in ductility. Our analysis of the dynamic mechanical behaviors and initial textures of AZ31B suggests that plastic deformation is mainly dominated by dislocation slip (basal and nonbasal). Furthermore, the maximum flow stress at high strain rates is much lower than that at its corresponding quasi-static counterpart.

The yield stress $\left(\sigma_{s}\right)$ of the metals is largely dependent on the CRSS of the various operating deformation mechanisms. By analyzing the variation in $\sigma_{s}$ with strain rate, the sensitivity of the 


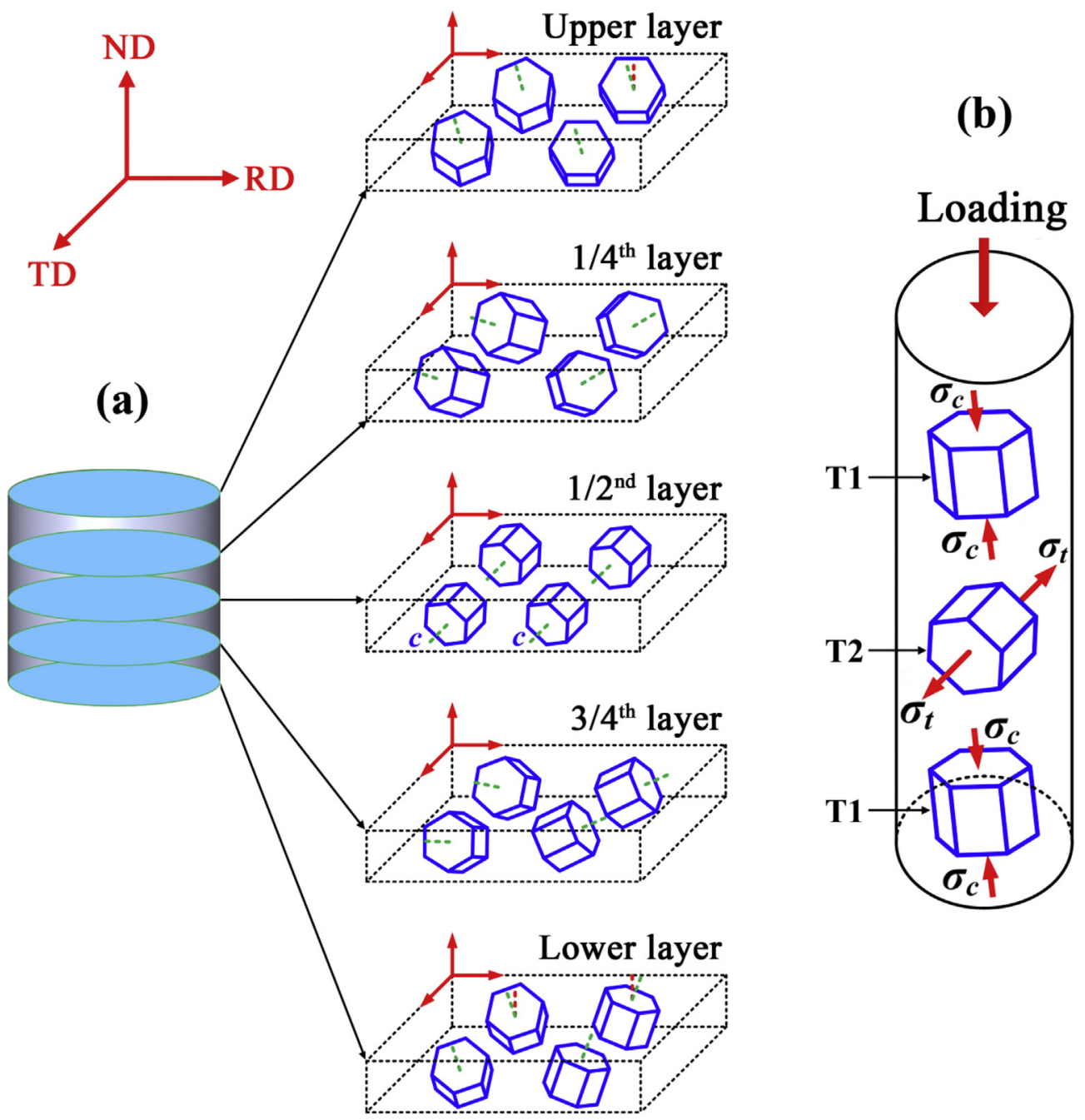

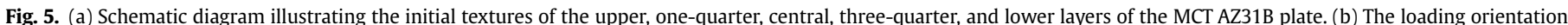
with respect to the $c$-axes.

CRSS of the operative deformation modes to strain rate can be approximately inferred. $\sigma_{\mathrm{s}}$ can be expressed as [17].

$\sigma_{s}=m \tau_{0}+m k d^{-1 / 2}$,

where $m$ is the Taylor factor, $\tau_{0}$ is the CRSS for dislocation slip, $k$ is the microstructural shear stress intensity that characterizes the resistance of grain boundaries to plastic deformation, and $d$ is the average grain size.

The flow stress corresponding to strain $\varepsilon=0.005, \sigma_{0.005}$, is used as a best approximation of the yield stress of a material under dynamic loading [17,22], as mentioned above. Variations in the yield stress $\left(\sigma_{0.005}\right)$ and maximum flow stress $\left(\sigma_{\max }\right)$ as a function of strain rate are shown in Fig. 6. $\sigma_{0.005}$ generally increases with increasing strain rate, with $\sigma_{0.005}$ at high strain rates being significantly higher than that at quasi-static strain rates. The performed analysis demonstrates that the plastic deformation mechanism of the MCT AZ31B is mainly of a dislocation slip type (basal and nonbasal). Many studies $[17,18,28]$ have confirmed that the CRSS for basal slip is insensitive to strain rate and temperature, whereas the CRSS for non-basal slip is greatly influenced by the strain rate, such that the CRSS increases with increasing strain rate. There is a certain degree of non-basal dislocations that occurs during dynamic deformation, as deduced from the results in Fig. 6, such that

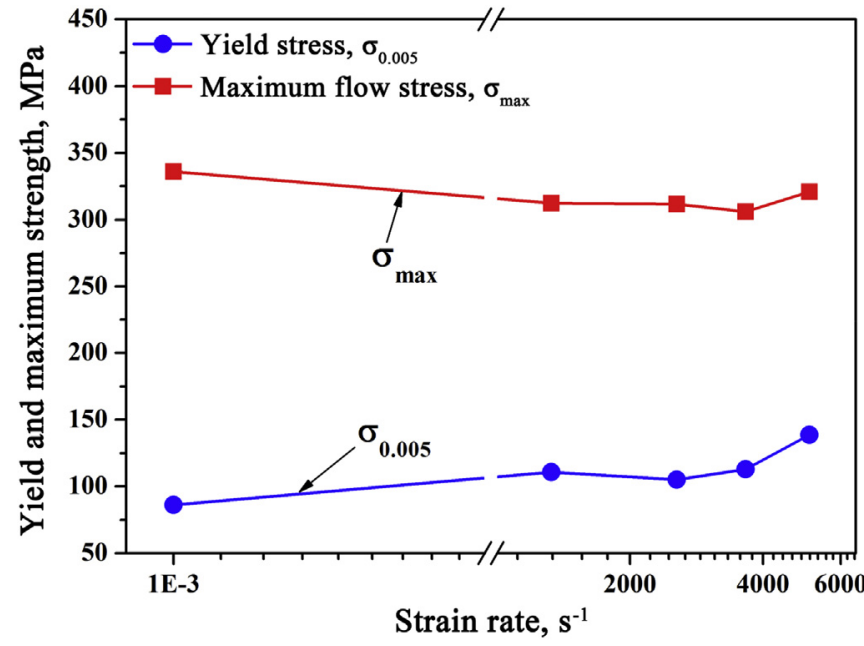

Fig. 6. Variations in the yield stress $\left(\sigma_{0.005}\right)$ and the maximum flow stress $\left(\sigma_{\max }\right)$ as a function of strain rate.

$\sigma_{0.005}$ increases with increasing the strain rate. $\sigma_{\max }$ gradually decreases with increasing strain rate, with $\sigma_{\max }$ at high strain rates 
being lower than that at quasi-static strain rates.

Both the strain hardening rate and strain rate sensitivity were analyzed as a function of true strain to further understand the mechanical behaviors of the MCT AZ31B. The strain hardening rate $(d \sigma / d \varepsilon)$ of the MCT AZ31B under high strain rate and quasi-static compression is shown in Fig. 7. Here $d \sigma / d \varepsilon$ is defined as the rate of change of the true stress-true strain curve, and is calculated by the numerical differentiation of the true stress-true strain data in Fig. 4. The $d \sigma / d \varepsilon$ curves at quasi-static and high strain rates $(d \varepsilon / d t \approx$ 1326-3651 $\mathrm{s}^{-1}$ ) have similar shapes and decrease with increasing strain (Fig. 7), exhibiting dislocation slip-dominated plastic deformation [17,22,35]. However, the $d \sigma / d \varepsilon$ curve at a strain rate of 5107 $\mathrm{s}^{-1}$ shows a multi-stage variation with increasing strain. The $d \sigma / d \varepsilon$ curve gradually decreases with increasing strain for plastic strain with $\varepsilon<0.06$ due to dislocation slip-dominated plastic deformation, whereas the $d \sigma / d \varepsilon$ curve significantly decreases with increasing plastic strain for plastic strain with $\varepsilon>0.06$ due to the occurrence of adiabatic softening.

Fig. 8 shows the variations in strain-rate sensitivity $(\beta)$ as a function of true strain and strain rate. $\beta$ is calculated from the true stress-true strain data presented in Fig. 4, and calculated as [36].

$\beta=\left(\frac{\partial \sigma}{\partial \ln \dot{\varepsilon}}\right)=\frac{\sigma_{2}-\sigma_{1}}{\ln \left(\dot{\varepsilon}_{2} / \dot{\varepsilon}_{1}\right)}$,

where the flow stresses $\sigma_{1}$ and $\sigma_{2}$ are obtained from dynamic mechanical tests performed at strain rates $\dot{\varepsilon}_{1}$ and $\dot{\varepsilon}_{2}$, respectively, and are calculated at the same strain value. Fig. 8 highlights that $\beta$ decreases significantly with increasing plastic strain and generally increases with increasing strain rate. Adiabatic softening took place for plastic strain with $\varepsilon>0.08$, resulting in a sharp decrease in $\beta$.

Analysis of the strain-rate sensitivity indicates that the flow stress is more sensitive to strain rate at the strain hardening stage (about $\varepsilon<0.08$ ). It is found that the flow stress is essentially rate sensitive when the plastic deformation is mainly dominated by the dislocation slip, which is consistent with previous results [17,18,28].

\subsection{Microstructure and texture evolution}

The controlled strain test and its corresponding microstructural characterization were conducted to investigate the plastic deformation mechanism of the MCT AZ31B at the initial plastic deformation stage. The metallographic microstructures and textures of the MCT AZ31B samples that underwent dynamic compression at a

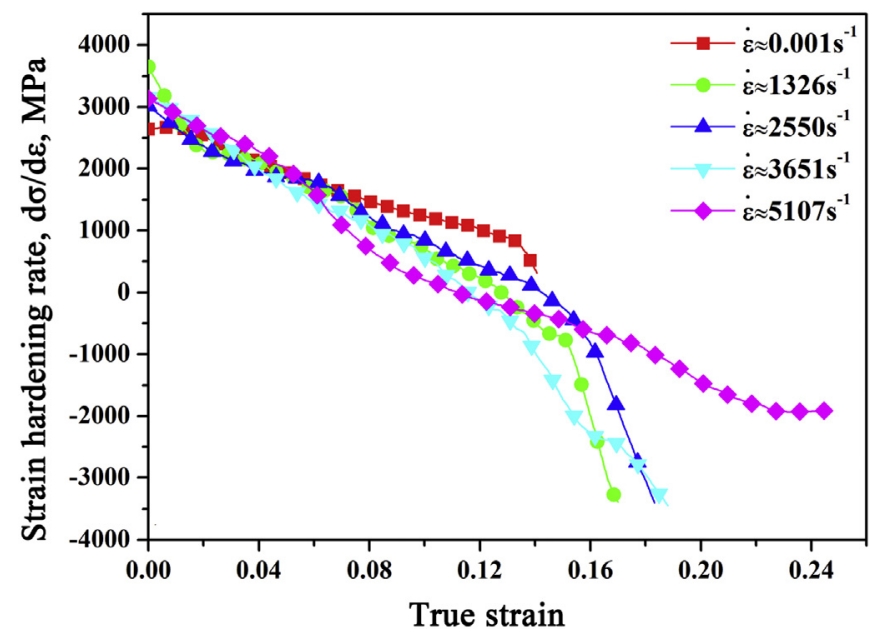

Fig. 7. Variations in strain hardening rate $(d \sigma / d \varepsilon)$ as a function of true strain.

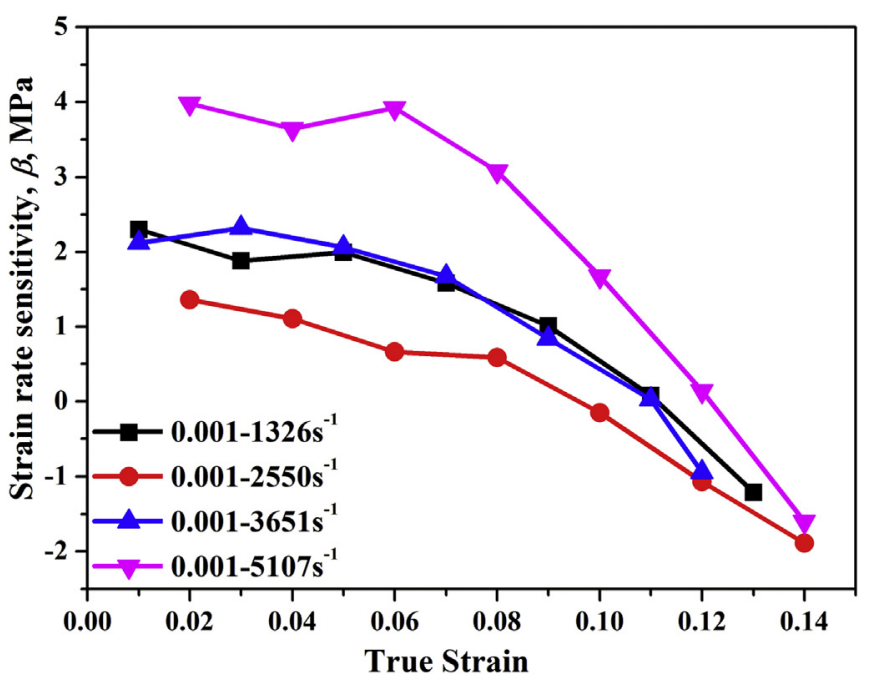

Fig. 8. Variations in strain-rate sensitivity $(\beta)$ as a function of true strain and strain rate.

plastic strain of $2.7 \%$ are shown in Fig. 9. The true stress-true strain curve of the controlled strain test is shown in Fig. 4. The metallographic microstructure along the longitudinal section of the deformed sample at $200 \times$ magnification consists of equiaxed grains, and no deformation twinning is observed (Fig. 9a). However, the metallographic microstructure of the same deformed sample in another observational field of view consists of relatively coarse, inhomogeneous grains and shows the presence of cracks (Fig. 9b). The metallographic microstructures of a deformed sample at $500 \times$ magnification clearly indicate that deformation twinning proceeds to a lesser extent, with a curved twin boundary (Fig. 9c and d).

The textures of a sample after the dynamic controlled strain test are shown in Fig. 9e. It should be noted that the test sample is machined from the interval between the one-quarter and threequarter layers of the AZ31B plate, as shown in Fig. 9f. As explained above, the initial textures of this interval are composed of two types of textures, the near basal-type and prismatic-type textures. Fig. 9e illustrates the weak basal-type texture of the sample after dynamic compression, where the c-axes are tilted away by almost $25^{\circ}$ from the ND. This further demonstrates that the prismatic-type texture in the AZ31B plate is very limited (because the prismatic-type texture under this loading condition will form a strong basal-type texture), with plastic deformation mainly controlled by the near basal-type texture.

Analysis of the deformed microstructures and textures of the MCT AZ31B demonstrates that the initial plastic deformation of the material is mainly controlled by a dislocation slip. Cracks initiated and propagated during the early deformation stage, with a deteriorative effect on the mechanical properties. It is therefore considered that the microstructures possess the characteristics of a layered distribution along the plate ND, such that the intergranular compatibility is poor during the plastic deformation, which leads to the stress concentration and crack initiation.

Microstructural evolution analysis can improve our understanding of the deformation mechanisms. The microstructural evolution of the MCT AZ31B under compression in the ND at quasistatic and high strain rates $\left(d \varepsilon / d t \approx 1326-5107 s^{-1}\right)$ is shown in Fig. 10. All the metallographic microstructures shown in Fig. 10 are obtained from the longitudinal sections of the deformed samples. The metallographic microstructures of a sample after quasi-static compression are shown in Fig. $10 \mathrm{a}-\mathrm{c}$ to serve as a reference to high strain-rate compression. Shear failure basically occurred at the 

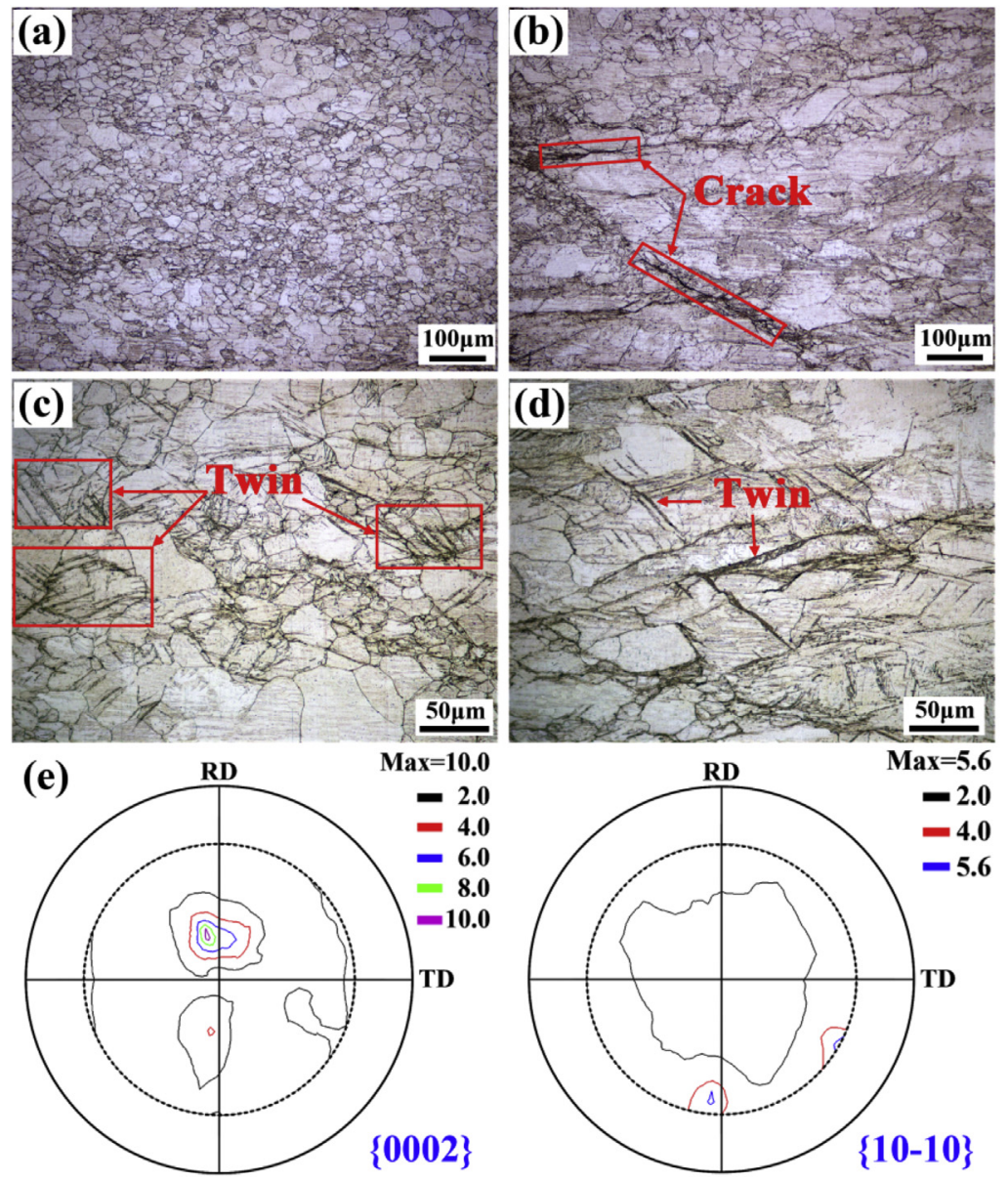

(f)

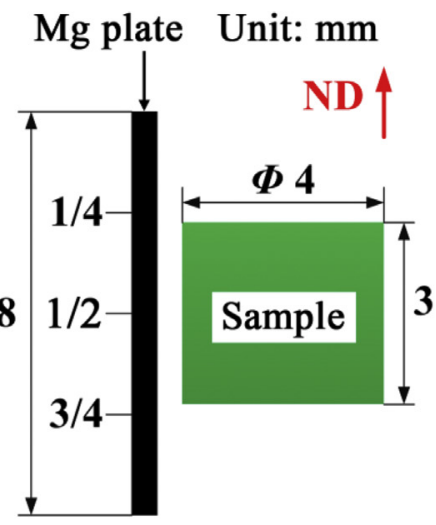

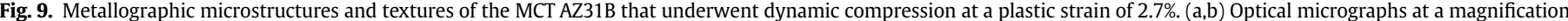

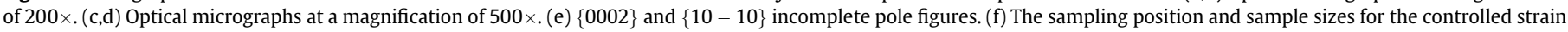
test in the AZ31B plate.

central area of the cylindrical samples during quasi-static compression, with the metallographic observation region close to the middle (near to the fracture surface) of the sample, which is primarily in the central region of the AZ31B plate. A large number of deformation twins are formed during deformation, with significant crack propagation, as shown in Fig. 10a-c. The deformation twins are densely distributed around the crack (Fig. 10a and b). The central region of the AZ31B plate has a prismatic-type texture, as discussed above. The $c$-axis is subjected to the tension when under compression along the ND, which is favorable for the formation and development of $\{10-12\}$ extension twinning.

The metallographic microstructures of a sample after dynamic compression at a strain rate of $1326 \mathrm{~s}^{-1}$ are shown in Fig. 10d-f. There is a clear evidence of the initiation and propagation of the cracks in different regions of the material, whereas the deformation twins are only observed in some local regions (Fig. 10e and f). The metallographic microstructures of a sample after dynamic compression at a strain rate of $3651 \mathrm{~s}^{-1}$ are shown in Fig. $10 \mathrm{~g}-\mathrm{i}$. The deformed microstructure is characterized by cracks and an adiabatic shear band (ASB), with more intensive crack formation and propagation as the strain rate increases. There are also present significant deformation twins around the cracks, and a sharp shear deformation zone exists at the crack tip (Fig. 10h). The primary ASB is clearly developed, along with a large number of deformation twins and fine secondary ASBs present (Fig. 10i). It is also found that deformation localization is more intensive with an increasing strain rate. The metallographic microstructures of a sample after dynamic compression at a strain rate of $5107 \mathrm{~s}^{-1}$ are shown in Fig. $10 \mathrm{j}-1$. Significant DRX took place at this high strain rate. However, the occurrence of DRX in the deformed sample is not homogeneous, with some weaker areas present (Fig. 10k and l). In addition, the mechanical response of the MCT AZ31B compressed at a strain rate of $5107 \mathrm{~s}^{-1}$ exhibits an obvious adiabatic softening behavior during the latter deformation stage, which can be well understood by a significant occurrence of DRX, thus enhancing the ductility of the material. It is reported that the occurrence of DRX may be attributed to the activation of a non-basal slip and the temperature rise produced during the high strain-rate deformation [37].

The microstructural evolution analysis indicates that the contribution of twinning to plastic deformation of the MCT AZ31B under high strain-rate compression is not significant. In addition, the initiation and propagation of cracks during deformation are common. DRX occurred under a higher strain-rate compression, though it is not uniform, which results in a moderate increase in the ductility of the material. The metallographic microstructures have a layered distribution along the ND, resulting in poor plastic deformation compatibility, which makes it prone to stress concentration and cracking during the plastic deformation.

XRD studies of the textures were conducted on the same samples that were examined in Fig. 10 to further investigate the plastic deformation mechanisms of the MCT AZ31B under high strain-rate deformation. It should be mentioned that texture analysis could not 

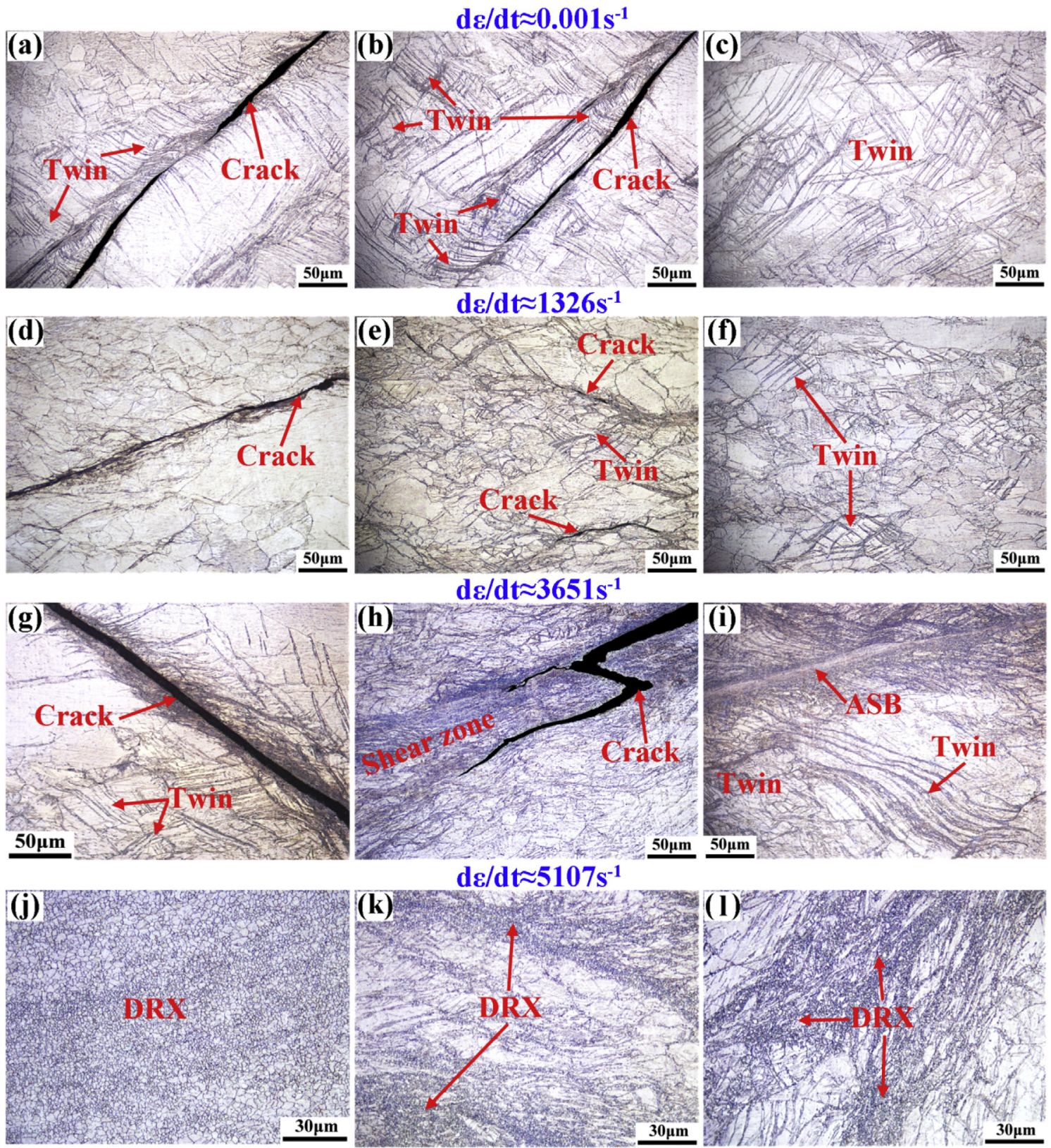

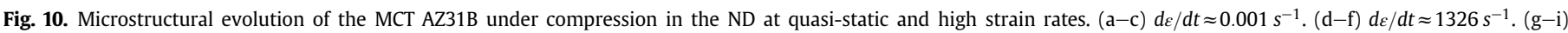
$d \varepsilon / d t \approx 3651 \mathrm{~s}^{-1}$. $(\mathrm{j}-\mathrm{i}) d \varepsilon / d t \approx 5107 \mathrm{~s}^{-1}$.

be performed on the samples compressed at a strain rate of 5107 $\mathrm{s}^{-1}$, because the samples were seriously smashed during the dynamic testing. The texture evolution of the MCT AZ31B after compressed in the ND at the quasi-static and high strain rates is shown in Fig. 11. The texture of a sample after quasi-static compression is shown in Fig. 11a, which serves as a reference to the high strain-rate compression. It is clear that the deformed sample has a near basaltype texture, where the $c$-axis deviates by about $20^{\circ}$ from the ND. Note that the texture measurement plane was selected near the fracture surface of the deformed sample. As illustrated in Fig. 10, a shear failure occurs near the central layer (prismatic-type texture) of the quasi-static test sample. The formation and development of $\{10-12\}$ extension twinning is substantial due to the compression along the ND. It is thus proposed that the near basal-type texture mainly attributed to the considerable formation of extension twinning.

The textures of the samples after a compression at high strain rates $\left(d \varepsilon / d t \approx 1326-3651 s^{-1}\right)$ are shown in Fig. $11 \mathrm{~b}-\mathrm{d}$. Shear failure took place in all the test samples during the dynamic compression. The texture measurements should be made as close as possible to the fracture area to truly reveal the texture variations of the material after dynamic deformation, in which severe deformation occurred. The location of the texture measurement is near the one-quarter or three-quarter layers of the MCT AZ31B plate. The textures in these regions are near basal-type textures, as identified in Fig. 2b and d. The tendency of $\{0002\}$ basal-type texture formation increases with increasing strain rate, but no strong $\{0002\}$ basal texture is formed (Fig. 11b-d). It is noted that a double-peak $\{0002\}$ basal texture was developed in the sample after dynamic compression at a strain rate of $1326 \mathrm{~s}^{-1}$ (Fig. 11b). This double-peak 

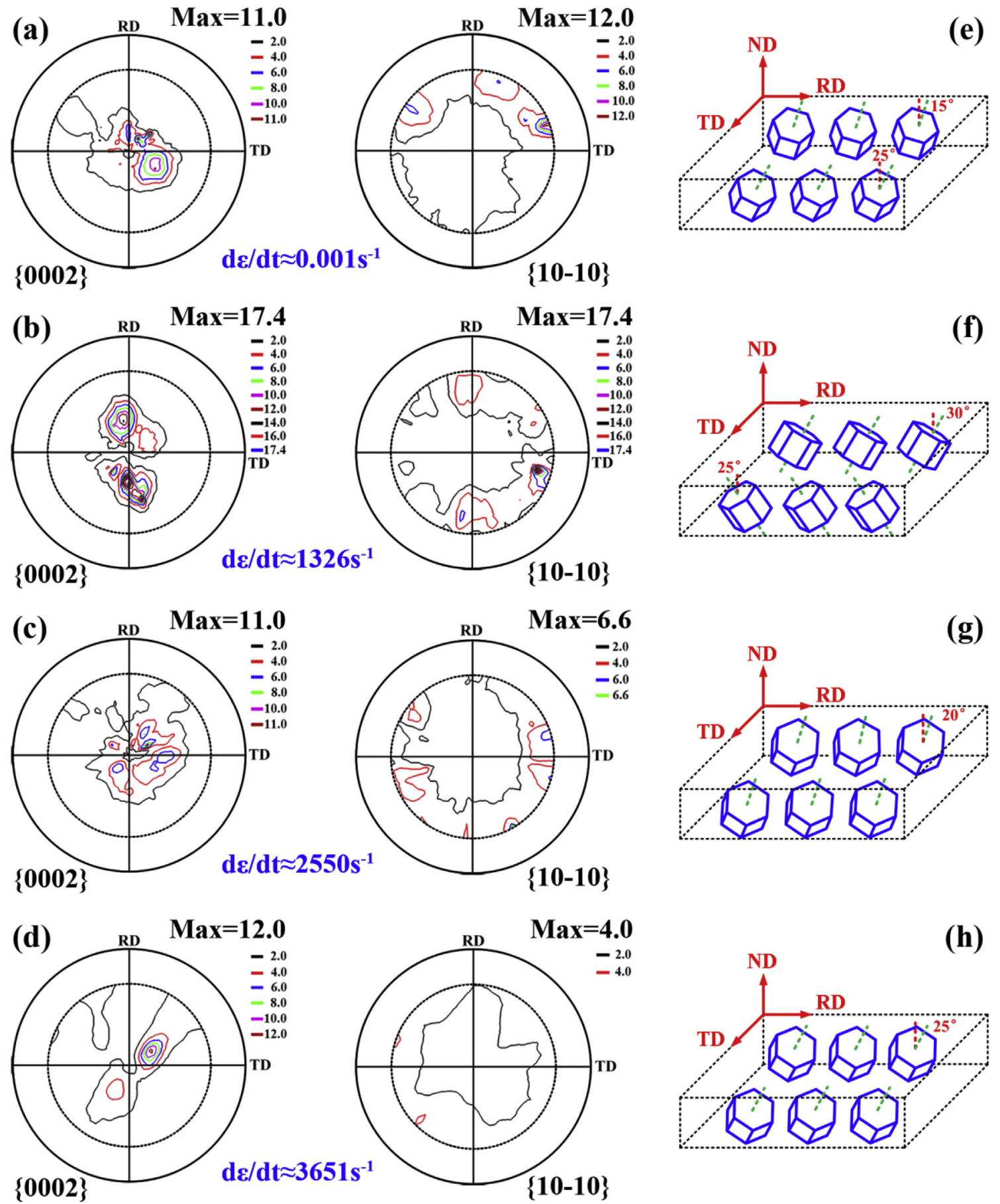

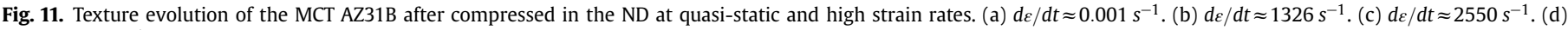
$d \varepsilon / d t \approx 3651 s^{-1}$. (e-h) Three-dimensional schematic diagrams of the deformed textures in accordance with Fig. 11a-d.

basal texture in the Mg alloy after high strain-rate or low strain-rate deformation has been observed before [18,20,27,34]. It is reported that $c+a$ dislocation slip plays an important role in rotating the basal poles, which leads to the splitting of the basal poles. TEM observations of the deformed sample possessing the double-peak basal texture shows that a high density of $c+a$ dislocations was produced during deformation. Fig. $11 \mathrm{e}-\mathrm{h}$ shows the threedimensional schematic diagrams of the deformed textures that correspond to Fig. $11 \mathrm{a}-\mathrm{d}$, which assist in improving our understanding of the texture evolution.

The enhanced formation of the $\{0002\}$ basal texture in a sample after a high strain-rate compression is mainly due to the dislocation slip, with extension twinning having only a marginal influence on the textural changes. The texture evolution in Fig. 11 further indicates that the predominant plastic deformation mechanism of the MCT AZ31B under high strain-rate compression is dislocation slip.

\subsection{Analysis of dislocation substructure}

TEM analysis was conducted on the MCT AZ31B samples compressed at high strain rates to gain further insight into the plastic 
deformation mechanism. The bright field TEM micrographs of a sample compressed at a strain rate of $1326 \mathrm{~s}^{-1}$ are shown in Fig. 12. High-density dislocations were produced during deformation (Fig. 12a), and the dislocations accumulated against the grain boundaries (Fig. 12b). The intensive formation of deformation twins, as well as the accumulation and pile-ups of dislocations inside twins and at the twin intersections, are shown in Fig. 12c-e. The selected area electron diffraction pattern (SADP) for the deformation twin marked by the blue circle in Fig. 12e is shown in Fig. 12f. The SADP result indicates that the twin system is $\{10-11\} 10-1-2$ contraction twinning. It should be noted that the TEM micrographs of the MCT AZ31B here are obviously different from those of the Mg alloy having an initial prismatic-type texture that is compressed under identical loading conditions. $\mathrm{Mg}$ alloys with an initial prismatic-type texture would generate $\{10-12\}$ extension twinning followed up by a significant development during early plastic deformation, with the entire grain quickly consumed during deformation. It is therefore difficult to observe deformation twins in the deformed microstructures $[24,28,38]$. Contraction twins are formed to a certain extent and retained in the deformed microstructure of the MCT AZ31B, indicating that the plastic deformation of the MCT AZ31B is mainly controlled by dislocation slip (basal and non-basal).

The bright field TEM micrographs of sample compressed at a strain rate of $3651 \mathrm{~s}^{-1}$ are presented in Fig. 13. It is clear that highdensity dislocations were produced during dynamic compression (Fig. 13a and b), with a typical dislocation cell formed due to the dislocation-dislocation interactions (Fig. 13c). Deformation twins were also formed, and the accumulation and pile-ups of dislocations was observed inside twins (Fig. 13d), similar to the TEM microstructures shown in Fig. 12. The high-density dislocations around the second phase in Fig. 13e indicate that the second phase can act as a strong barrier to dislocation motion. The SADP for the deformation twins marked by the blue circle in Fig. 13d is shown in Fig. 13f. This result validates that the twin system is also a $\{10-11\} 10-1-2$ contraction twinning. The TEM results highlight that the dislocation density increases with increasing strain rate, with the dislocation cell structure being more prone to form at a higher strain rate. The increasing strain rates will result in a continued increase in temperature during dynamic deformation, leading to the increased probability of the activation of increased amount of the slip dislocations [26,27]. Although the dislocation
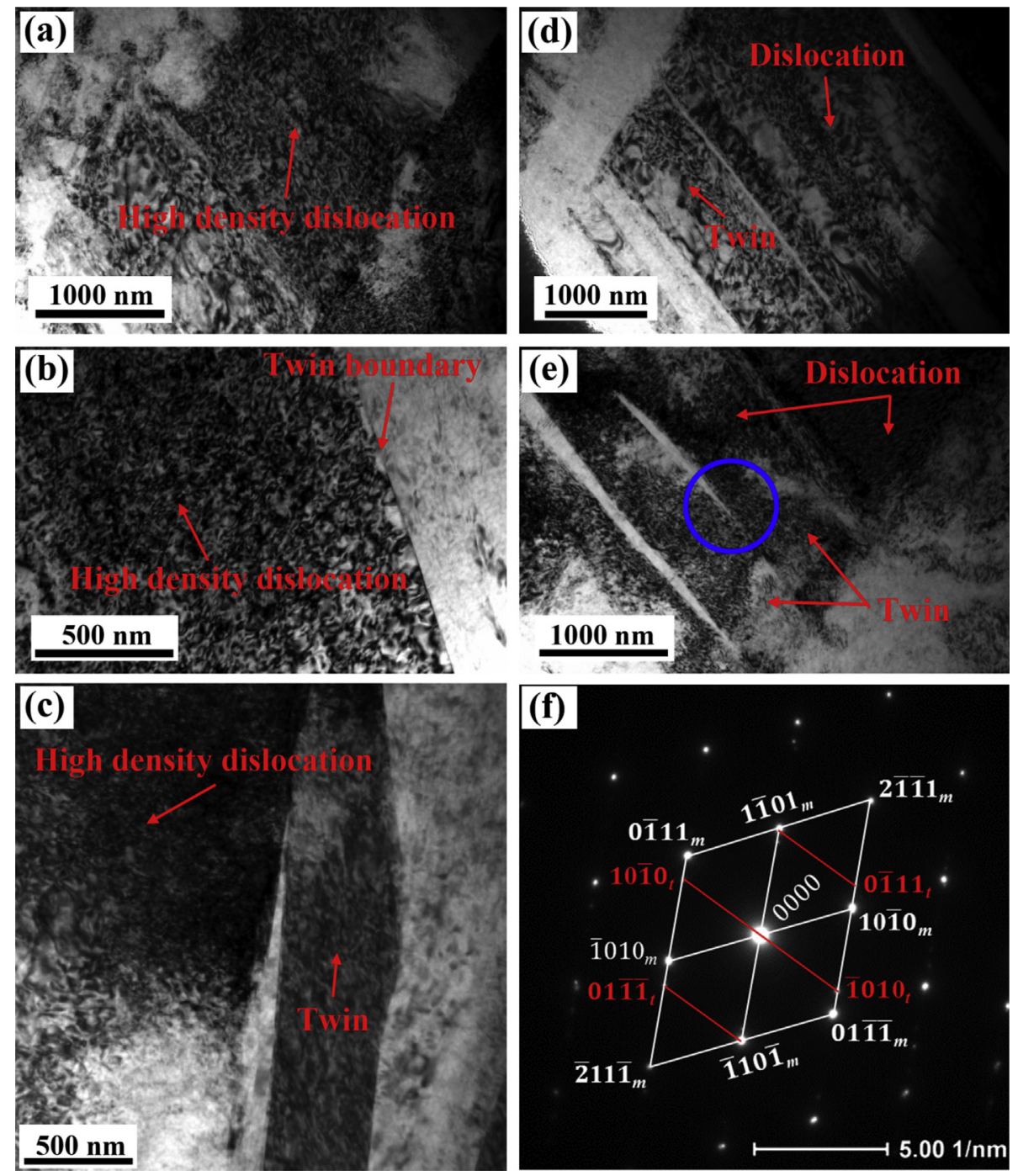

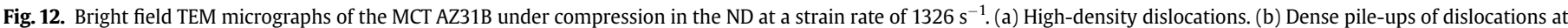

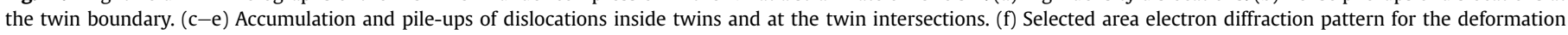
twins marked by the blue circle in Fig. 12e. (For interpretation of the references to colour in this figure legend, the reader is referred to the Web version of this article.) 

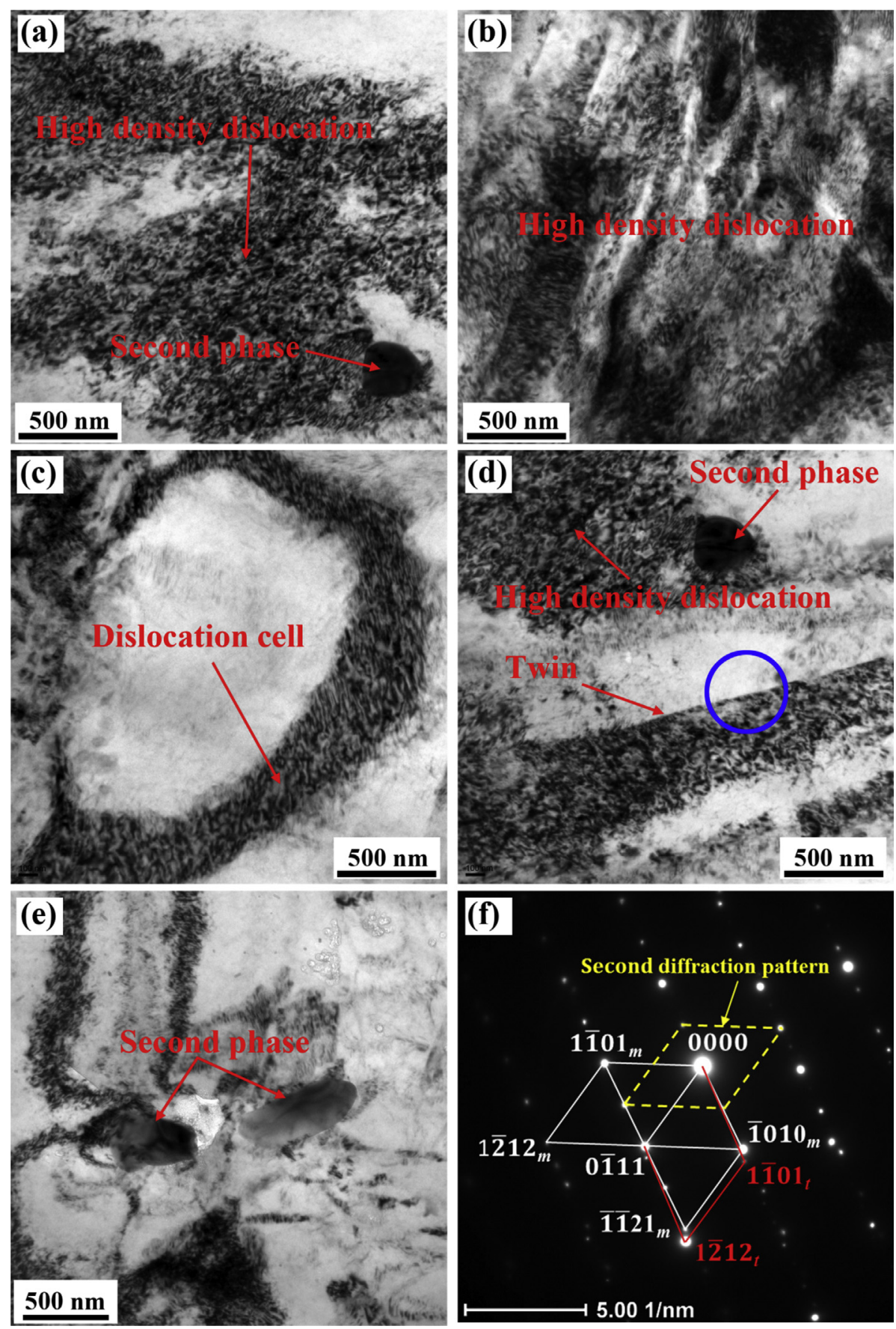

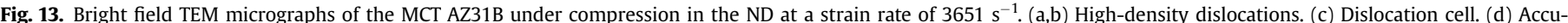

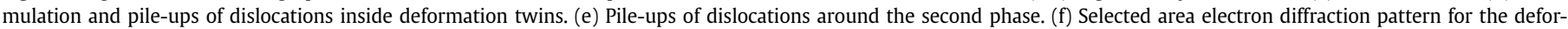

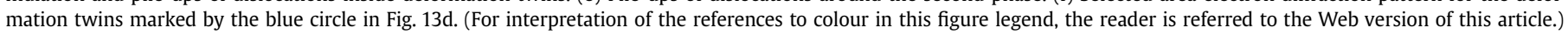

density is difficult to accurately measure due to serious dislocation-dislocation entanglement, the dislocation density of $\mathrm{Mg}$ and its alloys after high strain-rate $\left(\sim 10^{3} \mathrm{~s}^{-1}\right)$ deformation was estimated to be around $\sim 10^{14} \mathrm{~m}^{-2}$ [16].

High-density dislocations and strong dislocation-twin interactions were observed in the TEM micrographs of the MCT AZ31B under high strain-rate compression (Figs. 12 and 13). Dislocation pile-ups and twin intersections could be effective parameters in increasing the flow stress and strain hardening during plastic deformation. Furthermore, the stress concentration caused by the pile-ups of dislocations at the twin boundary can be alleviated through dislocation-twin interactions, which favors dislocation slip in the twin zone. High-density dislocations, deformation twins, and dislocation-twin interactions have been commonly observed in many Mg alloys during dynamic deformation, such as AZ31B [20], ZK60 [24], AE42, and AE44 [39].

It is concluded from Figs. 12 and 13 that the significant highdensity dislocations are produced during the high strain-rate deformation, with $\{10-11\} 10-1-2$ contraction twins formed to a certain extent. Furthermore, the interactions of dislocation-dislocation, twin-dislocation, and twin-twin intersections are more remarkable, leading to an increase in the flow 
stress and strain hardening. The TEM results indicate that plastic deformation of the MCT AZ31B under high strain-rate compression is mainly accommodated by dislocation slip.

The effect of microstructural evolution on the mechanical properties of a material can be estimated by examining its microhardness. Variations in the Vickers microhardness of the MCT AZ31B after compression in the ND at quasi-static and high strain rates are shown in Fig. 14. Microhardness measurements were conducted on the longitudinal section of the deformed sample, with the average value given. The initial microhardness of the MCT AZ31B is $59 \mathrm{HV}$. The microhardness of AZ31B compressed at quasistatic and high strain rates $\left(d \varepsilon / d t \approx 1326-3651 s^{-1}\right)$ are basically the same, at 80-82 HV. The microhardness of AZ31B compressed at a strain rate of $5107 \mathrm{~s}^{-1}$ and after the dynamic controlled strain test are 74 and $79 \mathrm{HV}$, respectively. The AZ31B after quasi-static and high strain-rate $\left(d \varepsilon / d t \approx 1326-3651 s^{-1}\right)$ compression has the highest microhardness, with the microhardness slightly decreasing after a further increase in the strain rate to $5107 \mathrm{~s}^{-1}$.

The MCT AZ31B under different strain-rate loadings has different microhardness values that reflects the different microstructural characteristics at the corresponding strain rates. The microhardness of AZ31B compressed at quasi-static and high strain rates in the $1326-3651 \mathrm{~s}^{-1}$ range has the highest value, indicating that the highest density of dislocations was produced at these conditions. The TEM observations of AZ31B compressed at strain rates of 1326 and $3651 \mathrm{~s}^{-1}$ also confirmed the formation of highdensity dislocations (Figs. 12 and 13). In addition, the microhardness of AZ31B after the dynamic controlled strain test is much lower than that under quasi-static and dynamic $\left(d \varepsilon / d t \approx 1326-3651 s^{-1}\right)$ compression, which indicates that the dislocations are only produced to a lesser extent in the initial stage of plastic deformation, leading to a lower dislocation density as compared to the other mentioned cases. DRX takes place when the strain rate is increased to $5107 \mathrm{~s}^{-1}$, which causes the dislocation density decreases, as well as a moderate decrease in microhardness compared with those at lower strain rates $\left(d \varepsilon / d t \approx 1326-3651 s^{-1}\right)$.

\subsection{Analysis of dynamic fracture behavior and absorption energy capacity}

The fracture behavior and failure mechanism of the materials

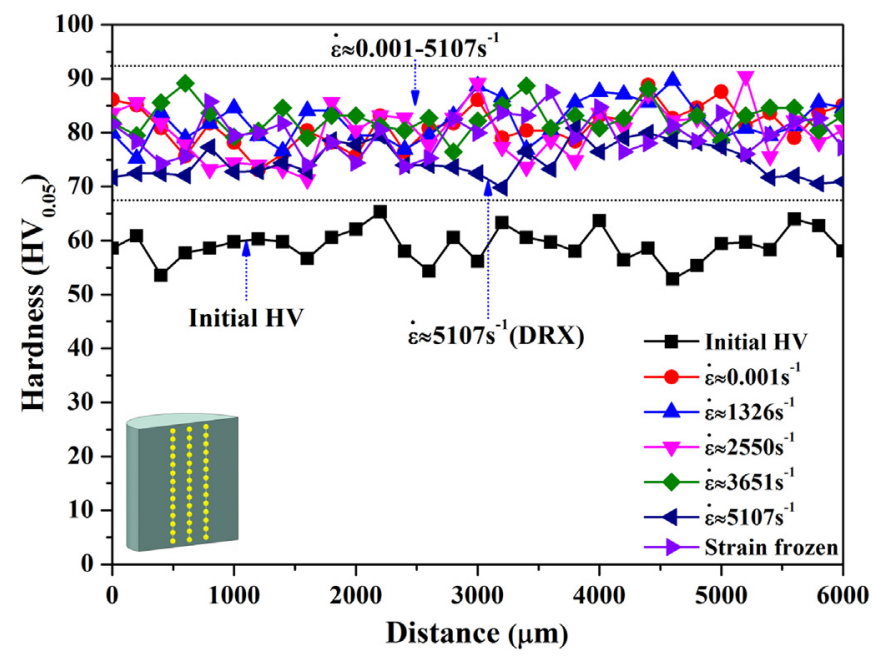

Fig. 14. Variations in Vickers microhardness of the MCT AZ31B after compression in the ND at quasi-static and high strain rates. can be better understood by analyzing their fracture morphology. SEM fractographs of the MCT AZ31B after compression in the ND at quasi-static and high strain rates are shown in Fig. 15. The fractographs of a sample after quasi-static compression serve as a reference to the high strain-rate compression (Fig. 15a-c), with the fracture surface demonstrating that a quasi-cleavage fracture had occurred since it is relatively flat and smooth (Fig. 15a). Furthermore, micro-cracks (Fig. 15b) and micro-dimples (Fig. 15c) are also observed in some localized areas. The fractographs of a sample after compression at a strain rate of $1326 \mathrm{~s}^{-1}$ are presented in Fig. $15 \mathrm{~d}-\mathrm{f}$. The observed fracture characteristics are similar to those in Fig. $15 a-c$, where the whole fracture surface of a sample under dynamic compression is relative flat, with micro-cracks (Fig. 15e) and micro-dimples (Fig. 15f) in some localized areas, thus indicating a quasi-cleavage fracture mode. The fractographs of a sample after a compression at a strain rate of $3651 \mathrm{~s}^{-1}$ are shown in Fig. $15 \mathrm{~g}-\mathrm{i}$. It is obvious that the fracture morphology undergoes significant changes at this loading strain rate, with prominent melting at the fracture surface (Fig. 15h and i) and micro-cracks still present in localized areas (Fig. 15g). The fractographs of a sample after compression at a strain rate of $5107 \mathrm{~s}^{-1}$ are presented in Fig. 15j-l. Significant amounts of micro-dimples are produced during deformation at the highest loading strain rate (Fig. 15j), and the degree and range of melting at the fracture surface are further expanded (Fig. 15k). Fig. $15 \mathrm{l}$ provides a higher magnification of the melting morphology marked by the red rectangle in Fig. 15k, where the occurrence of melting and increased micro-dimples at the fracture surface suggests that the deformation behavior of AZ31B becomes more ductile at higher strain rates.

The fracture behaviors of $\mathrm{Mg}$ alloys under dynamic loading have been previously examined by numerous researchers. Feng et al. [21] investigated the tensile properties of the AZ31B Mg alloy at high strain rates $\left(\sim 10^{3} \mathrm{~s}^{-1}\right)$, where the fracture mode of the $\mathrm{Mg}$ alloy changed from quasi-cleavage fracture to ductile fracture with increasing strain rate. The plasticity of the material under dynamic loading was also enhanced due to the dominant softening effect. Song et al. [40] investigated the dynamic compressive properties of AM series Mg alloys, and indicated that the number of microdimples on the fracture surface increased with increasing strain rate, resulting in an enhanced ductility. The fracture morphology of the DP 1000 and M 1200 steels under dynamic deformation was primarily composed of these typical dimple patterns as well [41]. The plasticity of the steels was thus enhanced under dynamic loading. Our fracture investigations of the MCT AZ31B under high strain-rate deformation are consistent with these previous results $[21,40,41]$.

Fracture behavior analysis indicates that significant melting took place in the severe deformation regions of the materials under high strain-rate deformation. The fracture behavior highlights a transition from a brittle fracture, which is characterized by a quasicleavage pattern, to a ductile fracture, which is characterized by micro-dimples and melting zones, as the strain rate increases. The high ductility of the MCT AZ31B under compression at a high strain rate $\left(\sim 10^{3} \mathrm{~s}^{-1}\right)$ is at least partially due to the transition in the fracture behavior from a brittle fracture model to a ductile one.

The absorption energy density and deformation-induced temperature rise of the MCT AZ31B during compression in the ND at quasi-static and high strain rates $\left(d \varepsilon / d t \approx 1326-5107 \mathrm{~s}^{-1}\right)$ are shown in Fig. 16. The energy absorption per unit volume $(\Delta E)$ is determined by integrating the uniaxial true stress-true strain curve. This deformation-induced temperature rise $(\Delta T)$ is due to both rapid mechanical deformation and lack of time to dissipate heat through the material. The dynamic deformation process is assumed to be adiabatic, with most of the strain energy (about 90\%) 

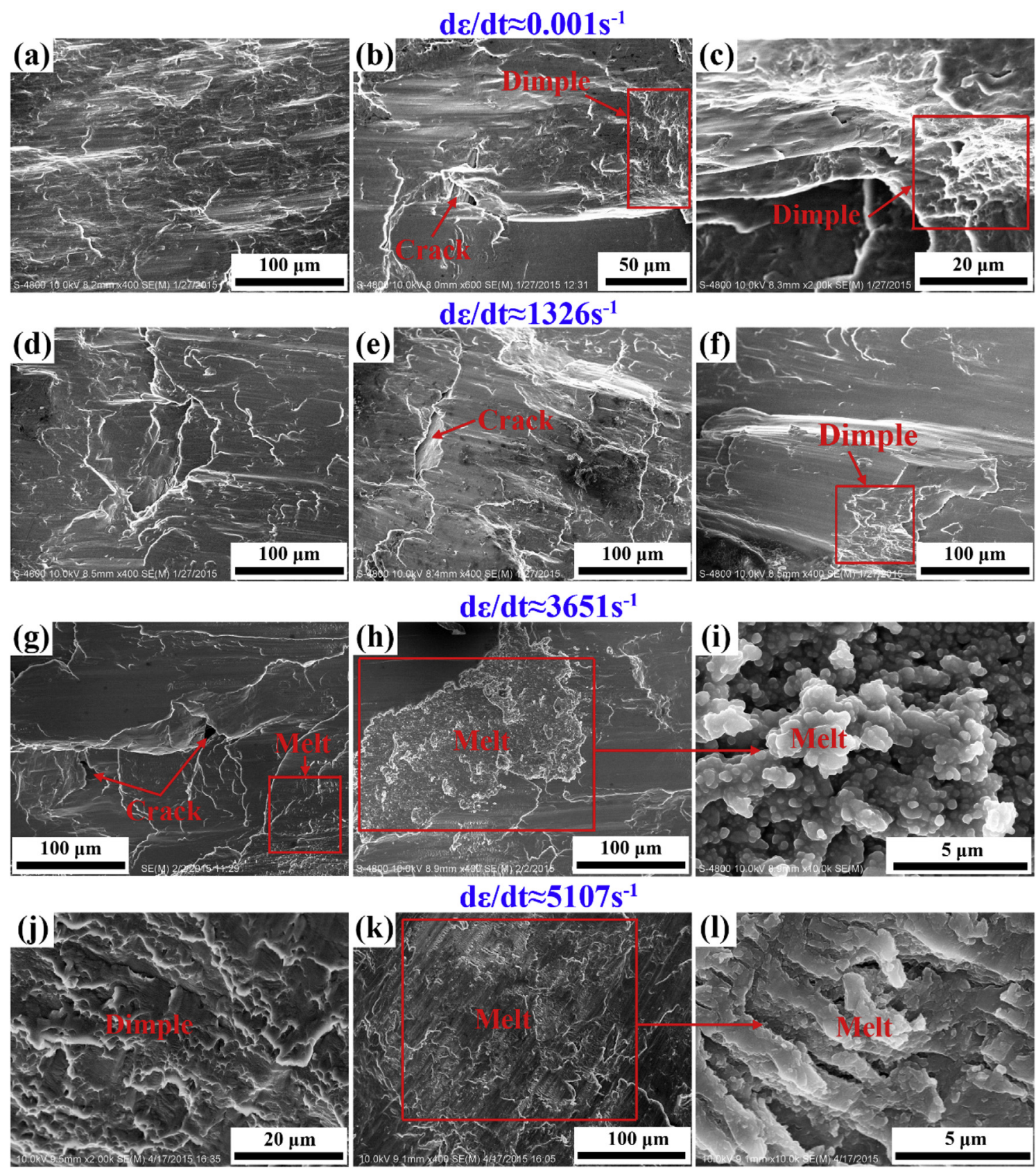

Fig. 15. SEM fractographs of the MCT AZ31B after compression in the ND at quasi-static and high strain rates. (a-c) $d \varepsilon / d t \approx 0.001 \mathrm{~s}^{-1}$. (d-f) $d \varepsilon / d t \approx 1326 \mathrm{~s}^{-1}$. (g-i) $d \varepsilon / d t \approx 3651 \mathrm{~s}^{-1}$. $(\mathrm{j}-\mathrm{l}) \mathrm{d} \varepsilon / \mathrm{dt} \approx 5107 \mathrm{~s}^{-1}$

transformed into heat. $\Delta E$ and $\Delta T$ can be determined as follows [42,43]:

Temperature rise $(\Delta T): \quad \Delta T=\frac{\eta}{\rho c_{p}} \int \sigma d \varepsilon$

Absorption energy density $(\Delta E): \quad \Delta E=\int \sigma d \varepsilon$

where $\rho$ and $c_{p}$ are the density and the specific heat capacity at constant pressure of the tested material, respectively, and $\eta$ is the proportion of work converted to heat. These parameters are as follows for MCT AZ31B: $\rho=1780 \mathrm{~kg} \mathrm{~m} \mathrm{~m}^{-3}, c_{p}=1040 \mathrm{~J} /(\mathrm{kg} \cdot \mathrm{K})^{-1}$, and $\eta=0.90$.
It is clear that $\Delta T$ increases as the strain rate increases, with the maximum value attained at $30 \mathrm{~K}$. The temperature rise in the bulk material is below $30 \mathrm{~K}$ during the dynamic $\left(\sim 10^{3} \mathrm{~s}^{-1}\right)$ deformation of metals [44]. However, the $\Delta T$ results indicate that this is not enough to affect the deformation behavior and mechanical properties of AZ31B. It should be noted that the $\Delta T$ calculated by Eq. (3) is the average temperature rise of the sample during the plastic deformation. The SEM fracture surface observations show that severe melting occurred at the fracture surface during the high strainrate deformation, indicating that the temperature rise is very significant in some regions that undergo a strong degree of deformation. Furthermore, the temperature is high enough to melt the AZ31B Mg alloy.

The energy absorption calculations show that $\Delta E$ increases 


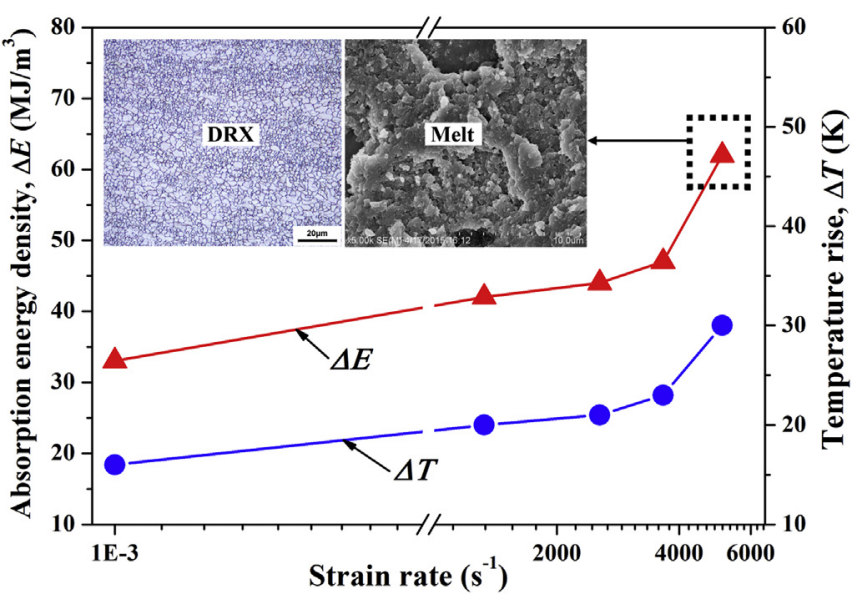

Fig. 16. Absorption energy density $(\Delta E)$ and deformation-induced temperature rise $(\Delta T)$ of the MCT AZ31B during compression in the ND at quasi-static and high strain rates. The metallographic microstructure of the longitudinal section and fracture morphology of sample after compression at a strain rate of $5017 \mathrm{~s}^{-1}$ are shown in the inset, which indicate that DRX took place in the microstructure and significant melting occurred on the fracture surface.

obviously with increasing strain rate, reaching a maximum value of $62 \mathrm{MJ} \mathrm{m}^{-3}$. Agnew et al. [43] have investigated the energy absorption capacity of a rolled WE43B Mg plate and extruded AM30 $\mathrm{Mg}$ alloy under compression along the ND and ED at a strain rate of $\sim 1000 \mathrm{~s}^{-1}$, where they obtained $\Delta E$ values of $66 \mathrm{MJ} \mathrm{m}^{-3}$ and $18 \mathrm{MJ} \mathrm{m}^{-3}$ for WE43B and AM60, respectively. The higher yield strength, in combination with the moderate ductility, was responsible for the higher $\Delta E$ in WE43B, with the lower $\Delta E$ in AM30 due to its lower yield strength and fracture strain. The $\Delta E$ for the MCT AZ31B here is slightly lower than that for WE43B, but it is more than that for AM30. Microstructural analysis of the deformed MCT AZ31B samples shows that a significant DRX occurred during the high strain-rate deformation, leading to an increase in ductility. Furthermore, the fracture behavior changes from brittle to ductile fracture as the strain rate increases, which can also enhance the ductility of the material. Thus, it is concluded that conspicuous DRX and brittle-ductile transitions are mainly responsible for the higher energy absorption capacity of the MCT AZ31B under high strain-rate deformation.

\section{Conclusions}

In present study, we investigated the high strain-rate deformation behavior and the microstructural evolution of the MCT AZ31B Mg alloy plate, fabricated by the ATRC process. The deformation mechanisms and fracture behaviors of the materials were elucidated through characterization and analysis of the deformed microstructures. The main conclusions of this study are listed below.

(1) The mechanical behaviors of the MCT AZ31B under compression along the plate ND at high strain rates in the 1326-5107 $\mathrm{s}^{-1}$ range exhibit a power-law hardening response. The flow stress is more sensitive to the strain rate at the strain hardening stage (about $\varepsilon<0.08$ ), and generally increases with increasing strain rate, whereas the strain hardening rate gradually decreases with increasing strain. It is found that the maximum flow stress of AZ31B at high strain rates is much lower than its corresponding quasi-static counterpart.
(2) It is concluded that the layered texture and microstructure characteristics along the plate ND determine the mechanical behavior of the MCT AZ31B. The plastic deformation behavior is mainly determined by the basal-type textures, and the predominant deformation mechanism is dislocation slip (basal and non-basal). The microstructures and textures have a layered distribution along the plate ND, leading to inhomogeneous plastic deformation and poor intergranular compatibility during deformation. Cracks initiated and propagated at the initial deformation stage, result in a decrease in maximum flow stress at high strain rates.

(3) DRX takes place during the high strain-rate deformation, but its extent and distribution is not homogeneous, resulting in a moderate increase in ductility. The fracture behavior shows a transition from a brittle fracture, which is characterized by the quasi-cleavage pattern, to a ductile fracture, which is characterized by micro-dimples and melting zones, as the strain rate increases. This DRX significantly enhances the energy absorption capacity of the MCT AZ31B, together with increased brittle-ductile transition at high strain rates.

\section{Acknowledgements}

This work was supported by National Natural Science Foundation of China (NSFC) under Contract No: 51471090.

\section{References}

[1] M.K. Kulekci, Magnesium and its alloys applications in automotive industry, Int. J. Adv. Manuf. Technol. 39 (2008) 851-865.

[2] M. Easton, A. Beer, M. Barneet, C. Davies, G. Dunlop, Y. Durandet, S. Blacket T. Hilditch, P. Beggs, Magnesium alloy applications in automotive structures, JOM 60 (2008) 57-62.

[3] A.A. Luo, Recent magnesium alloy development for elevated temperature applications, Int. Mater. Rev. 49 (2004) 13-30.

[4] C. Pohlmann, L. Röntzsch, S. Kalinichenka, T. Hutsch, B. Kieback, Magnesium alloy-graphite composites with tailored heat conduction properties for hydrogen storage applications, Int. J. Hydrogen Energy 35 (2010) $12829-12836$.

[5] H. Watanabe, H. Tsutsui, T. Mukai, M. Kohzu, S. Tanabe, K. Higashi, Deformation mechanism in a coarse-grained $\mathrm{Mg}-\mathrm{Al}-\mathrm{Zn}$ alloy at elevated temperatures, Int. J. Plast. 17 (2001) 387-397.

[6] S.R. Agnew, C.N. Tomé, D.W. Brown, T.M. Holden, S.C. Vogel, Study of slip mechanisms in a magnesium alloy by neutron diffraction and modeling, Scripta Mater. 48 (2003) 1003-1008.

[7] M.R. Barnett, Z. Keshavarz, A.G. Beer, D. Atwell, Influence of grain size on the compressive deformation of wrought $\mathrm{Mg}-3 \mathrm{Al}-1 \mathrm{Zn}$, Acta Mater. 52 (2004) 5093-5103.

[8] X.Y. Lou, M. Li, R.K. Boger, S.R. Agnew, R.H. Wagoner, Hardening evolution of AZ31B Mg sheet, Int. J. Plast. 23 (2007) 44-86.

[9] Y. Chino, K. Kimura, M. Mabuchi, Twinning behavior and deformation mechanisms of extruded AZ31 Mg alloy, Mater. Sci. Eng. A 486 (2008) 481-488.

[10] G. Proust, C.N. Tomé, A. Jain, S.R. Agnew, Modeling the effect of twinning and detwinning during strain-path changes of magnesium alloy AZ31, Int. J. Plast. 25 (2009) 861-880.

[11] M. Knezevica, A. Levinson, R. Harris, R.K. Mishra, R.D. Doherty, S.R. Kalidindi Deformation twinning in AZ31: influence on strain hardening and texture evolution, Acta Mater. 58 (2010) 6230-6242.

[12] A.S. Khan, A. Pandey, T. Gnäupel-Herold, R.K. Mishra, Mechanical response and texture evolution of AZ31 alloy at large strains for different strain rates and temperatures, Int. J. Plast. 27 (2011) 688-706.

[13] S. Mu, J.J. Jonas, G. Gottstein, Variant selection of primary, secondary and tertiary twins in a deformed Mg alloy, Acta Mater. 60 (2012) 2043-2053.

[14] N. Stanford, J. Geng, Y.B. Chun, C.H.J. Davies, J.F. Nie, M.R. Barnett, Effect of plate-shaped particle distributions on the deformation behaviour of magnesium alloy AZ91 in tension and compression, Acta Mater. 60 (2012) 218-228.

[15] T.A. Samman, G. Gottstein, Dynamic recrystallization during high temperature deformation of magnesium, Mater. Sci. Eng. A 490 (2008) 411-420.

[16] N. Dixit, K.Y. Xie, K.J. Hemker, K.T. Ramesh, Microstructural evolution of pure magnesium under high strain rate loading, Acta Mater. 87 (2015) 56-67.

[17] I. Ulacia, N.V. Dudamell, F. Gálvez, S. Yi, M.T. Pérez-Prado, I. Hurtado, Mechanical behavior and microstructural evolution of a Mg AZ31 sheet at dynamic strain rates, Acta Mater. 58 (2010) 2988-2998.

[18] N.V. Dudamell, I. Ulacia, F. Gálvez, S. Yi, J. Bohlen, D. Letzig, I. Hurtado, M.T. Pérez-Prado, Twinning and grain subdivision during dynamic 
deformation of a Mg AZ31 sheet alloy at room temperature, Acta Mater. 59 (2011) 6949-6962.

[19] C.Y. Gao, L.C. Zhang, W.G. Guo, Y.L. Li, W.R. Lu, Y.L. Ke, Dynamic plasticity of AZ31 magnesium alloy: experimental investigation and constitutive modeling, Mater. Sci. Eng. A 613 (2014) 379-389.

[20] H. Asgari, J.A. Szpunar, A.G. Odeshi, L.J. Zeng, E. Olsson, Experimental and simulation analysis of texture formation and deformation mechanism of rolled AZ31B magnesium alloy under dynamic loading, Mater. Sci. Eng. A 618 (2014) 310-322.

[21] F. Feng, S.Y. Huang, Z.H. Meng, J.H. Hu, Y. Lei, M.C. Zhou, D. W, Z.Z. Yang, Experimental study on tensile property of AZ31B magnesium alloy at different high strain rates and temperatures, Mater. Des. 57 (2014) 10-20.

[22] A. Pandey, F. Kabirian, J.-H. Hwang, S.-H. Choi, A.S. Khan, Mechanical responses and deformation mechanisms of an AZ31 Mg alloy sheet under dynamic and simple shear deformations, Int. J. Plast. 68 (2015) 111-131.

[23] C.S. Meredith, J.T. Lloyd, T. Sano, The quasi-static and dynamic response of fine-grained Mg alloy AMX602: an experimental and computational study, Mater. Sci. Eng. A 673 (2016) 73-82.

[24] B. Li, S.P. Joshi, O. Almagri, Q. Ma, K.T. Ramesh, T. Mukai, Rate-dependent hardening due to twinning in an ultrafine-grained magnesium alloy, Acta Mater. 60 (2012) 1818-1826.

[25] D. Orlov, M. Hockauf, L.W. Meyer, Y. Estrin, Dynamic properties of an ultrafine-grained Mg-Zn-Zr alloy, Phil. Mag. Lett. 93 (2013) 541-549.

[26] H. Asgari, A.G. Odeshi, J.A. Szpunar, On dynamic deformation behavior of WE43 magnesium alloy sheet under shock loading conditions, Mater. Des. 63 (2014) 552-564.

[27] H. Asgari, J.A. Szpunar, A.G. Odeshi, L.J. Zeng, E. Olsson, Effect of grain size on high strain rate deformation of rolled Mg-4Y-3RE alloy in compression, Mater. Sci. Eng. A 633 (2015) 92-102.

[28] K.E. Prasad, B. Li, N. Dixit, M. Shaffer, S.N. Mathaudhu, K.T. Ramesh, The dynamic flow and failure behavior of Magnesium and Magnesium alloys, JOM 66 (2014) 291-304.

[29] H. Zhao, P.J. Li, L.J. He, Microstructure and mechanical properties of an asymmetric twin-roll cast AZ31 magnesium alloy strip, J. Mater. Process. Technol. 212 (2012) 1670-1675.

[30] M. Masoumi, F. Zarandi, M.O. Pekguleryuz, Alleviation of basal texture in twin-roll cast Mg-3Al-1Zn alloy, Scripta Mater. 62 (2010) 823-826.
[31] M. Pankow, C. Attard, A.M. Waas, Specimen size and shape effect in split Hopkinson pressure bar testing. J. Strain Anal. Eng. Des, 44 (2009) 689-698.

[32] M.D. Nave, M.R. Barnett, Microstructures and textures of pure magnesium deformed in plane-strain compression, Scripta Mater. 51 (2004) 881-885.

[33] M.R. Barnett, M.D. Nave, C.J. Bettles, Deformation microstructures and textures of some cold rolled Mg alloys, Mater. Sci. Eng. A 386 (2004) 205-211.

[34] S.R. Agnew, Ö. Duygulu, Plastic anisotropy and the role of non-basal slip in magnesium alloy AZ31B, Int. J. Plast. 21 (2005) 1161-1193.

[35] G. Wan, B.L. Wu, Y.D. Zhang, G.Y. Sha, C. Esling, Anisotropy of dynamic behavior of extruded AZ31 magnesium alloy, Mater. Sci. Eng. A 527 (2010) 2915-2924.

[36] W.S. Lee, T.H. Chen, C.F. Lin, M.S. Chen, Impact deformation behaviour and dislocation substructure of Al-Sc alloy, J. Alloys Compd. 493 (2010) 580-589.

[37] L. Lu, J. Zhao, L. Liu, Z. Wang, Microstructural evolution and deformation behaviour of wrought $\mathrm{Mg}-\mathrm{Al}-\mathrm{Zn}$ alloys under dynamic compression, Mater. Sci. Technol. 32 (2016) 955-962.

[38] W.G. Zhang, Y.C. Ye, L.J. He, P.J. Li, H.S. Zhang, Dynamic mechanical response and microstructural evolution of extruded Mg AZ31B plate over a wide range of strain rates, J. Alloys Compd. 696 (2017) 1067-1079.

[39] H. Asgari, A.G. Odeshi, J.A. Szpunar, L.J. Zeng, E. Olsson, D.Y. Li, Effect of yttrium on the twinning and plastic deformation of AE magnesium alloy under ballistic impact, Mater. Sci. Eng. A 623 (2015) 10-21.

[40] W.Q. Song, P. Beggs, M. Easton, Compressive strain-rate sensitivity of magnesium-aluminum die casting alloys, Mater. Des. 30 (2009) 642-648.

[41] W. Wang, M. Li, C.W. He, X.C. Wei, D.Z. Wang, H.B. Du, Experimental study on high strain rate behavior of high strength 600-1000 MPa dual phase steels and 1200 MPa fully martensitic steels, Mater. Des. 47 (2013) 510-521.

[42] Q.Z. Li, Mechanical properties and microscopic deformation mechanism of polycrystalline magnesium under high-strain-rate compressive loadings, Mater. Sci. Eng. A 540 (2012) 130-134.

[43] S. Agnew, W. Whittington, A. Oppedal, H.E. Kadiri, M. Shaeffer, K.T. Ramesh, J. Bhattacharyya, R. Delorme, B. Davis, Dynamic behavior of a rare-earthcontaining $\mathrm{Mg}$ alloy, WE43B-T5, plate with comparison to conventional alloy, AM30-F, JOM 66 (2014) 277-290.

[44] D. Rittel, P. Landau, A. Venkert, Dynamic recrystallization as a potential cause for adiabatic shear failure, Phys. Rev. Lett. 101 (2008), 165501(1) -165501(4). 